Purdue University

Purdue e-Pubs

Open Access Theses

Theses and Dissertations

2013

\title{
Attitudes Towards the Use of Violence and Partner Directed Aggression
}

Joel G. Sprunger

Purdue University, joel.sprunger@gmail.com

Follow this and additional works at: https://docs.lib.purdue.edu/open_access_theses

Part of the Clinical Psychology Commons

\section{Recommended Citation}

Sprunger, Joel G., "Attitudes Towards the Use of Violence and Partner Directed Aggression" (2013). Open Access Theses. 100.

https://docs.lib.purdue.edu/open_access_theses/100

This document has been made available through Purdue e-Pubs, a service of the Purdue University Libraries. Please contact epubs@purdue.edu for additional information. 


\section{PURDUE UNIVERSITY \\ GRADUATE SCHOOL \\ Thesis/Dissertation Acceptance}

This is to certify that the thesis/dissertation prepared

By Joel G. Sprunger

Entitled

Attitudes Toward the Use of Violence and Partner Directed Aggression

For the degree of

Master of Science

Is approved by the final examining committee:

Christopher Eckhardt

Chair

Donald Lynam

Kipling D. Williams

To the best of my knowledge and as understood by the student in the Research Integrity and Copyright Disclaimer (Graduate School Form 20), this thesis/dissertation adheres to the provisions of Purdue University's "Policy on Integrity in Research" and the use of copyrighted material.

Approved by Major Professor(s): Christopher Eckhardt

Approved by: Christopher R. Agnew 


\title{
ATTITUDES TOWARDS THE USE OF VIOLENCE AND PARTNER DIRECTED AGGRESSION
}

\author{
A Thesis \\ Submitted to the Faculty \\ of \\ Purdue University \\ by \\ Joel G. Sprunger
}

In Partial Fulfillment of the

Requirements for the Degree

of

Master of Science

December 2013

Purdue University

West Lafayette, Indiana 


\section{TABLE OF CONTENTS}

LIST OF TABLES . . . . . . . . . . . . . . . . . . . . . . . iv

ABSTRACT . . . . . . . . . . . . . . . . . . . . . . .

INTRODUCTION . . . . . . . . . . . . . . . . . . . . . . . . . 1

Theoretical Models for IPV

Prior Research on Attitudes and IPV . . . . . . . . . . . . . . . 3

Measuring Attitudes . . . . . . . . . . . . . . . . . . . 5

Explicit Attitude Measurement . . . . . . . . . . . . 5

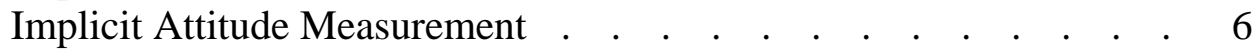

The Implicit Associations Test . . . . . . . . . . . . . . . . . . 8

The IAT and Aggression

The IAT and IPV . . . . . . . . . . . . . . . . . . . . . . . 10

Current Investigation . . . . . . . . . . . . . . . . . . . . . 11

METHOD . . . . . . . . . . . . . . . . . . . . . . . . 14

Participants. . . . . . . . . . . . . . . . . . . . . . . 14

Measures . . . . . . . . . . . . . . . . . . . . . . . 14

Partner Violence History . . . . . . . . . . . . . . . . . . . . 14

Attitudes Toward the Use of Violence . . . . . . . . . . 15

IAT D scores . . . . . . . . . . . . . . . . . . . . . . . 15

Attitudes About Aggression in Dating Situations Scale . . . 15

Acceptance of Violence Questionnaire . . . . . . . . . 16

Justification of Jealous and Coercive Tactics Scale. . . . . 17

Behavioral Aggression . . . . . . . . . . . . . . . . . . 17

Procedure and Materials . . . . . . . . . . . . . . . . . . . . . .

RESULTS . . . . . . . . . . . . . . . . . . . . . . . . 24

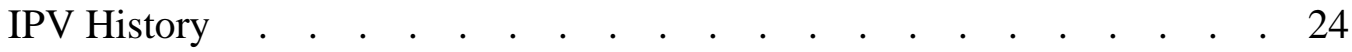

Explicit and Implicit Measures of Violence Attitudes . . . . . . . . 25

Implicit Measures of Violence Attitudes . . . . . . . . . 
Explicit Measures of Violence Attitudes . . . . . . . . . . . . 25

Inter-Relationships of Implicit and Explicit Violence Attitudes

Measures. . . . . . . . . . . . . . . . . . . 26

Behavioral Aggression . . . . . . . . . . . . . . . . . . 26

Voodoo Doll Task Pin Sticks . . . . . . . . . . . . . . . . . . 26

ATSS Aggression Variables . . . . . . . . . . . . . . . . . 27

Desired Behavior Inventory Aggression Variables . . . . . . . . . 28

IPV History and Implicit Violence Attitudes . . . . . . . . . . . . . 28

Attitudes Toward the Use of Violence as Moderation . . . . . . . . . 29

TPS-O . . . . . . . . . . . . . . . . . . . . . 29

DBI . . . . . . . . . . . . . . . . . . . . . . 29

Incremental Contribution of V-IAT D Scores . . . . . . . . . . 31

TPS-O . . . . . . . . . . . . . . . . . . . . . 31

$\mathrm{DBI} . . . . \quad . \quad . \quad . \quad . \quad . \quad . \quad . \quad . \quad . \quad . \quad . \quad .31$

DISCUSSION. . . . . . . . . . . . . . . . . . . . . . . 33

Limitations. . . . . . . . . . . . . . . . . . . . . 37

Conclusion. . . . . . . . . . . . . . . . . . . . . . 42

NOTES . . . . . . . . . . . . . . . . . . . . . . . . . 45

LIST OF REFERENCES . . . . . . . . . . . . . . . . . . . 46

\section{APPENDICES}

Appendix A. . . . . . . . . . . . . . . . . . . . . . . 54

Appendix B. . . . . . . . . . . . . . . . . . . . . . . . . . . 62

Appendix C. . . . . . . . . . . . . . . . . . . . . . . . . . . 63

Appendix D. . . . . . . . . . . . . . . . . . . . . . 64

Appendix E. . . . . . . . . . . . . . . . . . . . . . . . . . . . . 65

Appendix F. . . . . . . . . . . . . . . . . . . . . . . . . 67

Appendix G . . . . . . . . . . . . . . . . . . . . . . . . . . . . 68

Appendix H 


\section{LIST OF TABLES}

Appendix Table

Page

1. Demographic Data for Sample . . . . . . . . . . . . . . 54

2. Bivariate Correlations Among Explicit and Implicit Measures for the Full Sample . . . . . . . . . . . . . . . . . . . 55

3. CTS2 12-Month IPV Perpetration Values for the Full Sample. 56

4. Bivariate Correlations Between Violence-IAT D Scores or Explicit Violence Attitudes Measures and CTS2 12-Month IPV Variety Scores . . . . . . . . . . . . . . . . . . 57

5. Mean Comparisons for Outcome Variables by ATSS Condition and the Overall Sample . . . . . . . . . . . . . . . . 58

6. Mean Violence IAT D Scores by CTS2 IPV History for Current Sample Compared to Eckhardt et al. (2012). . . . . . . . . . . 59

7. Sequential Regression Analyses With ATSS Provocation Condition Contrast, Explicit, and Implicit Attitudes Predicting DBI Violent Aggression . . . . . . . . . . . . . . . . 60 


\begin{abstract}
Sprunger, Joel G. M.S., Purdue University, December 2013. Attitudes Toward the Use of Violence and Partner Directed Aggression. Major Professor: Christopher Eckhardt.
\end{abstract}

The present prospective study examined implicit and explicit attitudes toward the use of violence and their capacity to predict past and future partner-directed aggression in a nonclinical sample. Implicit violence attitudes were measured using a modified version of the Implicit Association Test. A battery of commonly-utilized explicit selfreport measures indexed explicit attitudes toward intimate partner violence (IPV). Measurement of violence attitudes occurred prior to engaging in the Articulated Thoughts in Simulated Situations behavioral aggression paradigm. Participants $(N=$ 81) were randomly assigned to conditions of imagined provocative ( $n=48$ ) or nonprovocative $(n=33)$ relationship scenarios and given the option to stick pins in dolls representing characters depicted in the scenarios. Simultaneously, participants “thought out loud” into a microphone about their thoughts. After the scenario, participants were provided with a list of physically and verbally aggressive behaviors and asked to indicate, if given the opportunity, their desire to have engaged in each behavior while they listened to the scenario. The results indicated that individuals with a history of recent psychological IPV perpetration showed more positive implicit 
attitudes toward violence relative to participants without a psychological IPV history. Implicit violence attitudes were unrelated to participant history of physical IPV perpetration. Explicit, but not implicit attitudes moderated the relationship between relationship provocation and the desire to engage in physically violent behavior. Implicit measures of violence attitudes did not show an incremental contribution toward the prediction of behavioral aggression on the present measures over and above explicit self-report measures of the construct. 


\section{INTRODUCTION}

Intimate partner violence (IPV) is a serious social concern in the United States, with devastating consequences that ripple beyond the dyad, through communities and society (Golding, 1999; Lawrence, Orengo-Aguayo, Langer, \& Brock, 2012).

Cognitive distortions and maladaptive beliefs regarding violence in relationships are associated with IPV perpetration (Eckhardt \& Dye, 2000; Eckhardt \& Jamison, 2002; Stith, Smith, Penn, Ward, \& Tritt, 2004) and are incorporated as fundamental components of major theoretical orientations regarding partner abuse (Murphy \& Eckhardt, 2005; Pence \& Paymar, 1993). Traditionally, distorted thought patterns and beliefs have been evaluated using explicit self-report measures (e.g., questionnaires) as the primary means of indexing the extent to which a person endorses such attitudes. Evidence has emerged indicating that, because IPV is largely deemed unacceptable within contemporary American society, explicit self-reports of IPV-related attitudes may produce inconsistent results and make the distinction between partner violent and nonviolent individuals difficult (Eckhardt, Samper, Suhr, \& Holtzworth-Munroe, 2012). Implicit measures, which assess attitudes through reaction time rather than conscious evaluation, have shown promise in distinguishing people with partnerviolent and nonviolent histories, suggesting promise for this alternative to explicit selfreport methods. The current prospective study examines the incremental contribution 
of an implicit measure of violence attitudes in the prediction of laboratory partnerdirected aggression, over and above which can be accounted for by traditional, explicit self-report measures of the construct.

\section{Theoretical Models for IPV}

Several theoretical models exist in the IPV literature to assist researchers and practitioners in how to organize the type and function of various risk factors for partner abuse. Each model conceptualizes IPV in terms of specific causal emphases and these inform assumptions about important etiological risk factors and targets of intervention or prevention efforts. Maladaptive beliefs and cognitive distortions are common across these models and their theoretical role in each will be discussed briefly in order to better appreciate the broad acceptance of violence attitudes as factors associated with IPV.

The traditional, and most dominant, theoretical model for understanding IPV is the feminist-sociocultural model. In this view, socialization within a patriarchal culture cultivates misogynist attitudes about male dominance and control over women, and the belief that men's coercive control tactics for subjugating women (e.g., via acts of physical and psychological aggression) are justified. These maladaptive attitudes are proposed to be direct causal influences of male-to-female partner-directed aggression and the primary target of batterer intervention programs guided by this model (e.g., the Duluth model; Pence \& Paymar, 1993). The cognitive-behavioral model for IPV views socialization factors as more distal influences toward aggression. Instead, the proximal focus of the cognitive-behavioral model is on distorted beliefs and assumptions, such as positive attitudes towards violence that overvalue the use of violence as an 
appropriate and effective solution to problems within the context of a relationship. Interventions conforming to this model focus on restructuring maladaptive attitudes towards violence and re-evaluating their ability to serve their intended function compared to less distorted beliefs. Interpersonal models of IPV conceptualize partnerviolence in terms of relationship systems involving both partners. Negative, abusive behaviors are often reciprocated in violent relationships and characterized by reactive and competitive interactions (Finkel \& Eckhardt, 2013; Jacobson et al., 1994; Murphy \& Eckhardt, 2005). Repeated participation in escalating negative interactions develops cognitive scripts for IPV. These scripts become automatic and overlearned sequences of cognitions, emotions, and behaviors that engage in response to commonly experienced conflict situations (Todorov \& Bargh, 2002). Interventions in this model focus on developing social skills and adaptive conflict resolution techniques that, although not necessarily stated in this theoretical orientation, weaken the automatic availability of aggression when arguments begin to escalate.

\section{Prior Research on Attitudes and IPV}

The etiological models of IPV described above presume that cognitive factors (e.g., distorted cognitive processing, violence attitudes, scripts for negative relationship interactions) are primary influences toward partner violence perpetration through motivational means (e.g., the belief that partners should be controlled through violent behavior) or part of a causal chain (e.g., seeing violence as an effective solution to conflict, distorted cognitive processing, automatic scripts for relationship violence). Research has provided a wealth of evidence to support maladaptive cognitions as risk factors for partner abuse. For example, IPV perpetrators tend to assume that their 
partners have negative intentions during imagined social interactions (Fincham, Bradbury, Arias, Byrne, \& Karney, 1997). Anger arousal increases the expression of cognitive distortions in imagined relationship scenarios (Eckhardt, Barbour, \& Davison, 1998). Partner abusers also misattribute blame for relationship conflict toward their partner (Fincham et al., 1997). Other research has shown a strong positive correlation between beliefs that favor blaming IPV victims and stronger positive attitudes toward interpersonal violence (Burt, 1980). Procriminal attitudes (e.g., the use of violence for goal achievement) are predictive of future criminal acts (Andrews $\&$ Bonta, 2010) and perpetrators of IPV have more positive attitudes toward the use of violence in their relationships than men who do not use violence against their partners (Sugarman \& Frankel, 1996). Attitudes regarding the use of violence appear to be available and commonly referenced for IPV perpetrators, as maritally-violent men produce fewer non-aggressive responses to relationship conflict relative to non-violent married men (Anglin \& Holtzworth-Munroe, 1997). A meta-analysis investigating predictive factors of partner violence indicated that attitudes towards the use of violence assessed by explicit self-report methods showed a medium effect size $(r=.30)$ in predicting partner violence perpetration (Stith et al., 2004). However, another metaanalytic examination revealed that social desirability responding has a moderate relationship with self-reported involvement in marital and courtship violence $(r=-.18)$ such that those with a greater tendency to present themselves in a more positive light also report less partner-violence perpetration (Sugarman \& Hotaling, 1997). Given that explicit self-report methods are prone to socially desirable responding, it is plausible that an effect size derived from responses to self-report measures of violence attitudes 
(e.g., Stith, et al., 2004) may underrepresent the relationship between these violence attitudes and partner-aggressive behavior, supporting the need for alternative methods of IPV attitude assessment. As the literature indicates, attitudes pertaining to the use of violence have severe consequences in relationships and, for the sake of prevention and intervention, it is paramount that their contribution toward IPV perpetration be more adequately measured and understood.

\section{Measuring Attitudes}

\section{Explicit Attitude Measurement}

Attitudes provide a wealth of information about an individual regarding the likelihood that the person will behave a certain way in a particular situation. The traditional and most common method for measuring these attitudes is the explicit selfreport questionnaire. Historically, this method has enjoyed success in part because of its ease of administration, cost-effectiveness, and ability to provide rich sources of information for attitudes that are frequently referenced by an individual (Greenwald et al., 2002; Paulhus \& Vazire, 2007). The way that people think about their behavior shapes their attitude about that behavior, as well as the likelihood of behaving similarly in the future (Albarracin \& Wyer, 2000). Meta-analytic findings indicated that easily accessible and stable attitudes regarding a specific topic or action are a strong source of information for predicting a person's relevant behaviors in the future and have shown significant predictive ability for everyday, socially-acceptable topics (Glasman \& Albarracin, 2006; Greenwald, Poehlman, Uhlmann, \& Banaji, 2009). As such, explicit self-reported measurement of easily accessible, non-stigmatized attitudes offers a 
reliable method for determining the likelihood that people will behave a certain way in the future.

Methods of explicit assessment impose limits to the extent that explicit measures are able to index certain attitudes. Explicit self-report measures are reliable to the extent that people are willing to report private information about themselves and have the ability to do so accurately (Greenwald et al., 2002). For attitudes regarding behaviors that are socially unacceptable, however, explicit self-report measures lose their ability to predict behavior (Greenwald et al., 2009). Compared with partner reports of their behavior, partner-abusive individuals tend to minimize the extent to which they perpetrate IPV (Archer, 2002; Ryan, 2013) and the tendency to downplay involvement in relationship violence has been shown to predict IPV perpetration (Scott $\&$ Straus, 2007). These findings suggest that an explicit self-report measure of violence attitudes may underrepresent the extent to which the person believes that violence is a viable and justified solution to interpersonal problems. The under-reporting behavior observed in this population regarding sensitive topics is likely the result of attempts by IPV perpetrators to present themselves in a positive light (Nosek, 2005; Fraley \& Marks, 2007). As such, it is probable that self-favoring biases negatively impact the accuracy with which explicit self-report measures of violence attitudes are able to provide researchers with meaningful information, thereby hampering the prediction of future IPV using these methods alone.

\section{Implicit Attitude Measurement}

Implicit methods of attitude assessment are an alternative to explicit measures. As stated above, explicit measures require the honesty and ability of individuals to 
report on their attitudes regarding constructs or behaviors of interest. At times, people may be unaware of the extent to which they hold certain attitudes and lack the ability to report them accurately. Explicit methods require conscious evaluation and response to an item on a questionnaire, while implicit methods measure attitudes at a level that is below conscious awareness (e.g., measurement of response latencies when a target and evaluation are paired to the same keystroke) and provide another way to index attitudes related to specific behaviors. Implicitly measured attitudes have shown significant relationships with behavior in a variety of domains. For example, Marquardt, Gades, and Robelski (2012) measured implicit attitudes for safety in the workplace and found that they predict risk-awareness and safety behaviors for industrial employees. Food choice between options varying in palatability is related to implicit health-related attitudes (Ayres, Conner, Prestwich, \& Smith, 2012). Voting behavior in the 2008 U.S. presidential election was shown to be predicted by implicit attitudes for racial preference, independent of explicit measures for the same construct (Greenwald, Smith, Sriram, Bar-Anan, \& Nosek, 2009). Implicit attitudes offer an alternative method of measuring attitudes that relates to behavior in the real world.

Implicit methods of attitude measurement have also shown promise for more accurate representation of attitudes toward socially stigmatized behaviors. Again, explicit measures rely on the honest and accurate reports from respondents. When individuals hold deviant views relative to those deemed acceptable by society at large, a person's willingness to report accurately and honestly on these attitudes decreases and they respond in socially-desirable ways (e.g., Eckhardt et al., 2012). Implicit measures, however, assess attitudes at a level that is below conscious awareness and, 
therefore, tend to be less susceptible to socially-desirable responding (Robertson \& Murachver, 2007; Greenwald, Nosek, \& Banaji, 2003; Greenwald et al., 2009).

Rudman and Ashmore (2007) showed that implicit race attitudes predicted the extent to which a person makes offensive racial comments and jokes independently of explicit measures for the construct. A recent investigation found that stronger negative implicit attitudes towards children with autism predicted professional burnout in educators and mental health professionals who work with this population more so than explicit measures (Kelly \& Barnes-Holmes, 2013). Overall, the evidence indicates that implicit methods provide valuable information regarding behavior and are able to contribute incremental evidence for a person's attitudes across a variety of socially-sensitive domains. We will now turn our attention toward the most commonly-used measure for indexing implicit attitudes.

\section{The Implicit Associations Test}

Implicit attitudes may be measured using a number of methods involving wordcompletion tasks, priming tasks, and evaluations of ostensibly neutral stimuli. The most common method, however, is the Implicit Association Test (IAT; Greenwald, McGhee, \& Schwartz, 1998) and most of the studies cited above reporting evidence linking implicit attitudes with behavior utilized some form of the IAT to conduct their investigation. The IAT is a latency-based computer task that pairs a target (e.g., violence or peaceful) with an attribution (e.g., good or bad) on the same keystroke over the course of many trials. The target-attribution pairs are then switched for an equal number of trials. Differences in response latencies between the two target-attribution pairings provides an indication of how closely each target is paired with a specific 
evaluation in a person's mind. More specifically, the less time a person requires to make a correct classification for a specific target-attribution pairing, the more closely the person has linked those concepts in their mind. The IAT was originally designed as a method for indirectly measuring attitudes regarding racial biases—a sociallysensitive topic. It has since been modified across many subject areas to measure associations between specific concepts (e.g., gender and violence) or a concept and an attribute (i.e., violence is good or bad). The IAT is especially useful for investigating attitudes less amenable to explicit self-report methods.

\section{The IAT and Aggression}

The IAT has been applied widely in investigations related to aggression. An IAT indexing violence attitudes was used to show that psychopathic criminals more rapidly associate violence as pleasant relative to a nonpsychopathic comparison (Gray, MacCulloch, Smith, Morris, \& Snowden, 2003). Implicit bullying attitudes measured with an IAT have been shown to act as moderators in predicting school bullying behavior for children with relatively positive explicit bullying attitudes (van Goethem, Scholte, \& Wiers, 2010). An aggression IAT was shown to predict aggressive behavior in children over and above the variance accounted for by explicit self-report measures (Grumm, Hein, \& Fingerle, 2011). Another aggression IAT indicated that the more closely one implicitly associates themselves with the attribute of aggressive, the more aggressively they respond to provocation (Richetin, Richardson, \& Mason, 2010). General aggression research has benefitted from incorporating the IAT as an implicit method of measuring associations among concepts and assessing attitudes. A 
narrowed focus will now examine the applications of IATs in studies investigating aggression in the context of intimate relationships.

\section{The IAT and IPV}

Implicit measurement of IPV-related attitudes offers a novel alternative to traditional self-report methods. In a recent study, Eckhardt et al., (2012) administered three IATs - modified for IPV-related constructs - and explicit traditional IPV questionnaires to men enrolled in an IPV treatment program and a group of nonviolent comparisons. The three IATs measured attitudes toward gender, violence, and the association linking gender and violence in the mind. Stronger positive implicit attitudes regarding violence and a stronger association between women and violence were shown to be present in partner-violent men relative to the nonviolent comparison group. Differences failed to emerge between groups on the explicit measures of IPV constructs, suggesting that explicit reports may lack sensitivity in the domain of IPV. Implicit violence attitudes were found to be correlated with both self-reported and partner-reported IPV perpetration frequency for men in the IPV prevention program such that those who report and are reported to perpetrate more frequent violence have closer associations linking violence with positive evaluations.

Implicit IPV attitudes were investigated in a recent study to examine their relationship with behavioral outcomes of IPV perpetrators mandated to attend partner violence interventions (Eckhardt \& Crane, in press). In this investigation, the same IPV IATs described above were administered along with explicit measures to a sample of IPV offenders recently adjudicated on partner violence charges. The researchers found that IAT effects indicating stronger associations linking violence with positive 
evaluations were associated with more past-year partner violence perpetration, greater treatment non-compliance, and criminal recidivism at a six-month follow-up. The explicit measures failed to predict prior-year violence and criminal re-offense, indicating again the important potential contribution of an implicit measure for violence attitudes in the assessment of IPV risk.

The above studies provide evidence that implicitly-measured violence attitudes are associated with prior violence and relevant behavior in the future. Eckhardt et al. (2012) showed implicit violence attitudes to distinguish IPV perpetrators from nonviolent comparisons. However, the retrospective, descriptive nature of this study makes it difficult to determine if these implicit attitudes indicate risk for future IPV perpetration or if prior partner violent acts have simply increased the efficiency with which violent words are associated with positive words for those individuals. Eckhardt and Crane (in press) found that implicit violence attitudes alone were associated with prior violence perpetration, poorer treatment compliance, and criminal recidivism when assessed six months after judicial sentencing for IPV charges. This study demonstrated that evidence regarding the ability of implicitly-measured violence attitudes to provide information regarding behavior six months in the future. What is needed is an investigation with an acute prospective focus in order to determine whether implicitlymeasured violence attitudes predict partner-directed aggression in a controlled laboratory setting and, thus, indicate an immediate risk factor for future IPV.

\section{Current Investigation}

Attitudes towards the use of violence are related to partner-violent behavior. Self-report measures have been widely used to assess violence attitudes in 
investigations of predictive relationships with violent behavior and have shown some success in doing so. However, self-reports are susceptible to tactics of imagepreservation and IPV perpetrators tend to demonstrate social desirability response biases. Implicit measures are less susceptible to these response biases and have been shown to successfully differentiate between IPV perpetrators and nonviolent individuals based on their implicit attitudes towards the use of violence. However, no study has yet applied these implicit violence attitudes toward the prediction of acute partner-violent behavior under controlled conditions. As such, the present study addresses the above methodological issues through an investigation of the relationship between attitudes toward the use of violence and aggressive behavior that incorporates both implicit and explicit measures of the construct. The predictive ability of these violence attitudes on acute subsequent behavioral aggression will be assessed in terms of aggressive responses to provocation in the laboratory.

First, I hypothesize that individuals with a self-reported history of physical IPV will show a greater violence IAT (V-IAT) effect such that their average response latencies will be shorter for trials in which violence is paired with a positive evaluation relative to those without a history of partner violence. Second, a predictive model containing both explicit and implicit violence attitude variables is anticipated to show that overall attitudes towards the use of violence moderate the provocation-behavioral aggression relationship (i.e., participants with more favorable explicit and implicit attitudes toward the use of violence will show a greater aggressive response to provocation than those with less favorable violence attitudes). Third, as implicit methods are less susceptible to social desirability, the V-IAT D scores are expected to 
show an incremental contribution toward the prediction of acute aggressive behavior in the laboratory above that which is accounted for by traditional explicit measures. 


\section{METHOD}

\section{Participants}

Participants $(N=100)$ were recruited for this study from a large Midwestern university as partial fulfillment of their research participation requirement for an introductory psychology course. They elected to participate in a study examining “close relationships and self-regulation resources.” Participants were at least 18 years of age and are currently or have been in a romantic heterosexual relationship in the past 12 months. The final sample $(n=81)$ consisted of male $(n=30)$ and female $(n=51)$ undergraduate students in the provocation $(n=48)$ and non-provocation $(n=33)$ conditions ${ }^{1}$. Participants were excluded from analysis because of missing data due to equipment malfunctions $(n=15)$, endorsing a non-heterosexual preference ${ }^{2}(n=2)$, and for stating their knowledge of the purpose of the study $(n=2)$. Demographic information of the final sample can be found in Table 1.

\section{Measures}

\section{Partner Violence History}

Self-reported history of partner violence perpetration was assessed by participant responses on the overall Psychological Aggression $(\alpha=.68)$ scale and the Minor $(\alpha=.60)$ and Severe Physical Aggression $(\alpha=.42)$ subscales of the Revised Conflict Tactics Scale (CTS2; Straus, Hamby, Boney-McCoy, \& Sugarman, 1996). 
The CTS2 is a well-validated and highly utilized measure for dating violence in the study of intimate partner violence. The specific subscales included in the current study totaled 20 items and were selected to index the extent to which a participant has perpetrated psychological and physical violence of graded severity within the past 12 months.

\section{Attitudes Toward the Use of Violence}

Explicit attitudes towards the use of violence were measured using several of the most commonly used measures of the construct in the IPV literature.

IAT D scores. The Violence IAT (V-IAT; Eckhardt et al. (2012) was used in the current investigation to measure the implicit association between 'violence' and 'good' for the participants. The V-IAT data were prepared by instituting a recommended $600 \mathrm{~ms}$ penalty for trials in which the participant's classification response was incorrect (Greenwald, Nosek, \& Banaji, 2003). V-IAT D scores were then calculated by subtracting the average response latency for the congruent (i.e., violence-bad) block from the incongruent (i.e., violence-good) block and dividing by the standard deviation of their performance across both blocks. According to this algorithm, more positive numerical values indicate a stronger violence-bad association and a less positive evaluation regarding the use of violence.

Attitudes About Aggression in Dating Situations Scale. The Attitudes About Aggression in Dating Situations Scale (AADS; Slep, Cascardi, Avery-Leaf, \& O'Leary, 2001) is a 12-item measures designed to assess the extent to which individuals agree with the use of aggression in dating situations for males and females. The items are divided so that five items depict scenarios in which a male aggresses against a female, 
five items depict a female aggressing toward a male, and two items depict aggression from a male and female toward a same-sex individual. All items depict the aggression within specific social contexts. For each item, participants indicated on a 6-point Likert-type scale how much they aggreed with the aggressive action depicted (i.e., $1=$ strongly agree; 6 = strongly disagree). The items were reverse-scored so that higher numbers indicated a stronger acceptance of the use of aggression in dating situations. The Male to Female Violence, Female to Male Violence, and Same-sex Peer scales combine to produce the AADS Total scale.

Acceptance of Violence Questionnaire. The Acceptance of Violence Questionnaire (AVQ; Riggs \& O'Leary, 1996) is a 12-item scale that assesses the extent to which a respondent feels the use of violence against an intimate partner is justified and an effective solution to relationship conflict. The first three odd items on the scale present acts of physical aggression by a male perpetrator against his girlfriend and participants are asked to respond using a 4-point Likert-type scale $(0=$ never; $4=$ always) for how often they believe this action is permitted during relationship conflict. The first three even numbers on the scale ask the respondent to indicated how often the depicted act of physical aggression is an effective solution to the relationship conflict for a male perpetrator. The final six items of the scale are the same as the first, but the perpetrator is now female. The AVQ yields the Justification and Problem-Solving scales consisting of participant responses to even and odd items, respectively with greater values indicating more positive attitudes regarding the appropriateness and effectiveness of violence in relationship conflicts. 
Justification of Jealous and Coercive Tactics Scale. The Justification of Jealous and Coercive Tactics Scale (JVCT; Slep, et al., 2001) is a 24-item scale that indexes an individual's attitudes regarding the justification of verbal aggression and controlling and jealous behaviors as directed toward an intimate partner. Half of the items on the scale assess how justified $(1=$ Justified in many situations; $5=N o t$ justified no matter what) a person believes a specific act of partner aggression is for a male perpetrator and the other half of items ask about the same acts but perpetrated by a female. The scale yields six subscales: the Justification of Male and Female Verbal Aggression, Justification of Male and Female Control Tactics, and Justification of Male and Female Jealousy Tactics. The items are reverse-scored and summed to produce the scores for their respective subscales, with larger scores indicated more positive attitudes regarding the use of verbal aggression, controlling behaviors and jealousy tactics against intimate partners by male and female perpetrators.

Copies of the items included from the CTS2 and AVQ are available in Appendices C and D. The AADS and JVCT are copyrighted materials and were not included for this reason. Measures of internal consistency for the scales of each measure are available along the diagonal in Table 2.

\section{Behavioral Aggression}

The Desired Behaviors Inventory (DBI) represented one method for measuring aggressive intentions in the current study. The 10-item DBI asked the participant to rate, on a 1 (not at all) - 7 (very much) scale, the degree to which they would want to engage in each of the listed behaviors. These behaviors included physically aggressive, verbally aggressive, and non-aggressive options. This method of assessing aggression 
was implemented to aid in assessing the likelihood that participants would engage in situation-relevant behaviors that were not possible to simulate in the laboratory setting, but indicative of their behavior in a similar real-world encounter. The two forms of the DBI are tailored to the ATSS scenario with which they are presented (see Appendix E). The items of the two forms are nearly identical, with shared sentence stems and scenario-specific referents. The two forms of the DBI combine to yield the Physical Aggression (DBI-PA), Verbal Aggression (DBI-VA), and Non-Aggressive behavior (DBI-NA) subscales. Reliabilities for the Verbal Aggression $(\alpha=.89)$ scale was acceptable. The Physical Aggression $(\alpha=.67)$ and Non-Aggressive $(\alpha=.73)$ scales showed a lower internal consistency. Greater scores on these scales indicate a greater degree to which participants wished to engage in these behaviors during the ATSS scenario, but were unable because of the inability to simulate the behaviors in the laboratory. As I am interested in examining the extent to which violence attitudes relate to aggressive behavior, only the DBI-PA and DBI-VA scales were used in the analyses of my hypotheses.

\section{Procedure and Materials}

Research participants entered the lab and were led to a desk with a computer monitor and keyboard (see Appendix F) by a trained undergraduate research assistant (RA). This research assistant role was referred to as the 'Primary' RA. The desk and computer were situated perpendicular to a two-way mirror, behind which was an observation control room and a second, 'Support' RA. While the participant was consented into the study, the Support RA flipped a coin to determine condition assignment (i.e., a "heads" result was the provocation condition and a "tails" results 
was the non-provocation condition) and this condition was entered into the MediaLab software (v. 2012.4; Empirisoft, 2012b) computer program. The study was explained to the participant and all questions were answered by the Primary RA before the participant provided their informed consent. The RA left the room while the participant completed several background questionnaires including a basic demographics form, the Revised Conflict Tactics Scale (CTS2; Straus et al, 1996), the Acceptance of Violence Questionnaire (AVQ; Riggs \& O'Leary, 1996), the Attitudes about Aggression in Dating Situations Scale (AADS; Slep, Cascardi, Avery-Leaf, \& O'Leary, 2001), and the Justification of Jealous and Coercive Tactics Scale (JVCT; Slep, et al., 2001) in order to assess their recent IPV history and self-reported attitudes toward the use of violence. Higher scores on these measures indicated a greater frequency of IPV perpetration in the past year, more positive attitudes regarding the use of violence, or greater propensity toward behaving aggressively across situations. A number of filler questionnaires assessing self-control techniques and positive relationship behaviors were also completed as part of the questionnaire battery in order to prevent aggression-priming effects ${ }^{3}$.

Following the first block of questionnaires, participants completed a modified IAT (Greenwald, et al., 1998) via the DirectRT software (v. 2012.4; Empirisoft, 2012a) designed to implicitly measure attitudes towards the use of violence (V-IAT; Eckhardt, et al., 2012) through differences in observed response times when categorizing violence words simultaneously with 'good' or 'bad' words on a computer. Words appeared on the computer screen and participants were asked to classify the words into the appropriate target category, with each category assigned to a particular keystroke 
(e.g., "VIOLENCE" words receive an "E" keystroke; "PEACEFUL" words receive an "I" keystroke). Participants were asked to do this as quickly as possible without making errors. During the next block of trials, particiants repeated the classification task with the attribution categories (e.g., "BAD" words receive an "E" keystroke; "GOOD" words receive an "I" keystroke). Then, a block of trials paired the target categories with the attribution categories in congruent (e.g., VIOLENCE-BAD on "E" key, PEACEFUL-GOOD on "I" key) or incongruent (e.g., VIOLENCE-GOOD on "E" key, PEACEFUL-BAD on "I" key) groupings. The order in which these congruent/incongruent target-evaluations were presented was counterbalanced across participants to avoid sequencing effects. Then, the target-evaluation pairing was switched so that the opposite evaluation word was paired with each target pole-if VIOLENCE-BAD was paired in the first combined block, the next combined block had VIOLENCE-GOOD on the same keystroke. The difference in response latency between the incongruent and congruent blocks (i.e., mean latency on the VIOLENCEBAD block minus the mean latency on the VIOLENCE-GOOD block, divided by the standard deviation of the person's overall response latency) resulted in the IAT score, represented as a $D$ statistic value between -2 and 2 (Greenwald, Nosek, \& Banaji, 2003). For this study, the IAT effect is the relative difference between the two targetevaluation comparisons such that a positive value close to 2 indicates a stronger association between violence words and their evaluation as "bad" in that person's mind. Conversely, the lower the IAT score relative to 2 , the more closely violence is associated with being "good" for that person. 
Following the V-IAT, the RA provided the participant with headphones and a microphone for the Articulated Thoughts during Simulated Situations paradigm (ATSS; Davison, Robins, \& Johnson, 1983). Using the modified ATSS for dating violence (Eckhardt, Barbour, \& Davison, 1998), participants in the provocation condition listened to an audio recording from the ATSS paradigm designed to induce anger via an imagined jealousy-based relationship scenario. This scenario required the participant to listen to, and imagine, going to their partner's place after class and overhearing a flirtatious exchange between their partner and an opposite-sex interloper. Participants in the non-provocation condition listened to a neutral scenario in which they imagined arriving to a restaurant before their partner for a date and listening to the couple at the next table have a conversation in the meantime. Each scenario is divided into 5 segments, with a 30 second pause between each segment for participants to "think out loud" about what is on their mind regarding themselves, their partner, and the events depicted in the scenario.

Aggressive behavior was measured with three different methods. The first measure was the Voodoo Doll task (see Appendix G). The Voodoo Doll task is a novel and valid measure of aggression (DeWall, et al., 2013). As the RA set up the table for the ATSS scenario presentation, they placed two dolls - each depicting a gendersecured to a wedge-shaped board, directly in front of the participant. A small tray of sewing pins was placed between the participant and the dolls, next to the microphone. The research assistant then explained to the participants, "Now, you will listen to a scenario through these headphones and imagine that you are taking part in that scenario. The people in the following scenario are not in the room with you now, so I 
want you to use these dolls and these pins to do to those people what you cannot do in real life as you listen." The Primary RA then provided the instructions for the ATSS task as follows: "As you listen, you will hear a 'beep' sound. When you hear the beep, think out loud, into the microphone, about your thoughts at that moment. You will have 30 seconds to talk about what you are thinking, feeling, and what you would like to do as you imagine each situation. The scenario will continue after you hear a second beep sound. Remember, this entire session is confidential and there are no right or wrong answers, so feel free to really speak your mind and tell us what you would like to do. Anything you say is appropriate and the more you say, the better."

Following the instructions for the Voodoo Doll Task and ATSS, the Primary RA answered all questions and then triggered the ATSS sequence on the computer. Next, the Primary RA left the experiment room to observe from the control room with the Support RA. To assess the Voodoo Doll dependent variables, both RAs monitored the pin penetrations in the dolls during the time period in which the participants are listening and reacting to their assigned ATSS scenario. More specifically, the number and location of pin insertions placed on each gendered doll were of interest, as attention to these details permitted a quantitative measurement of physically aggressive behavior by the participant. The frequency of verbally aggressive statements generated by participants during the 30 second response intervals of the ATSS scenario comprised the second measure of aggression. These verbalizations were transcribed and coded by two trained independent raters for physically aggressive (i.e., the expression of the desire behaviorally aggress against the taped character) and verbally 
aggressive statements (i.e., provision of statements intended to put down, demean, insult, or verbally engage a depicted character aggressively).

Following the ATSS scenario, the MediaLab program presented a third measure of aggression. This measure was a custom questionnaire, the Desired Behaviors Inventory (DBI), designed to accompany the specific ATSS scenario assigned to the participants. After participants completed this questionnaire, they notified the Primary RA and the manipulation check was performed. The manipulation check consisted of participant answers to the question "How did the scenario make you feel?" Participants were then debriefed by the Primary RA, provided with an education form describing the focus of the study in greater detail, compensated with participation credits toward their research requirement, and dismissed. 


\section{RESULTS}

\section{IPV History}

Twelve-month IPV perpetration rates were measured using the CTS2 to distinguish those participants who have perpetrated physical aggression against their partner in the past year $(n=28)$ from those who have not $(n=53)$. Percentages for perpetration of psychological and physical IPV are available in Table 3. Participants with a history of physical IPV made up 29.2\% $(n=14)$ of the ATSS provocation condition and $42.4 \%(n=14)$ of the ATSS non-provocation condition. A second scoring algorithm was used to indicate the number of different IPV acts perpetrated in the past year. This variety scoring method for response options on the Revised Conflict Tactics Scale (e.g., Moffitt et al., 1997) provides a better estimate of the severity of violence than frequency-based scoring, as less frequent, more severe acts may be overshadowed by more frequent, less severe acts (e.g., pushing, shoving, etc.) otherwise. Mean CTS2 psychological and physical IPV perpetration variety scores are available in Table 3. CTS2 IPV history variety scores were unrelated to the behavioral aggression outcome measures examined in this study (see Appendix H). 


\section{Explicit and Implicit Measures of Violence Attitudes}

\section{Implicit Measures of Violence Attitudes}

The mean V-IAT $D$ score $(M=.96, S D=.35)$ indicated that the overall sample appeared to be delayed in their responses during the incongruent condition and tended to show less positive attitudes towards the use of violence. Table 4 shows the bivariate correlations between CTS2 psychological and physical aggression variety scores and V-IAT $D$ scores. V-IAT $D$ scores shared a significant negative relationship with the variety scores for CTS2 psychological aggression such that individuals who perpetrate a greater number of different psychologically aggressive acts against their partner appear to have more positive implicit attitudes regarding violence, $r=-.32, p<.01$. VIAT scores did not share a significant relationship with CTS2 physical aggression, $r<$ $.00, n s$.

\section{Explicit Measures of Violence Attitudes}

Table 2 shows the bivariate correlations among the explicit measures for the overall sample. The total summary scores for the AADS, AVQ, and JVCT were significantly related, with correlations ranging from $r=.37$ to $r=.53$ (all $p$ 's $<.01$ ) and an average correlation of $r=.45$. Z scores were calculated for these four summary scores, summed, and then averaged into a single explicit attitudes composite variable. Table 4 provides the bivariate correlations between the explicit violence attitudes total scores used for the composite and CTS2 12-month IPV variety scores. The AVQ Total and JVCT Total Verbal Aggression scores shared significant positive relationships with physical IPV perpetration such that those who self-report more positive explicit 
attitudes towards the use of violence tend to have perpetrated a greater variety of physical IPV acts in the past 12 months $(r=.33, p<.01, r=.45, p<.01$, respectively).

\section{Inter-Relationships of Implicit and Explicit Violence Attitudes Measures}

Table 2 shows the bivariate correlations among the explicit and implicit measures for the overall sample. The V-IAT $D$ scores were significantly positively correlated with AVQ Total score $(r=.23, p<.05)$, indicating that participants who more closely associated violence with negative evaluations tended to report more explicit beliefs that violence is a justified and effective solution to relationship conflict on this measure.

\section{Behavioral Aggression}

\section{Voodoo Doll Task Pin Sticks}

Two trained undergraduate researchers observed the number of pins inserted into the male and female dolls during the ATSS scenario for each participant. Intraclass correlation analysis revealed a high degree of reliability in the ratings provided by the observers for both male $(\alpha=.90)$ and female dolls $(\alpha=.98)$. Their pin stick frequency observations were averaged to provide Total Pin Sticks in Male Doll (TPS-MD) and Total Pin Sticks in Female Doll (TPS-FD) outcome variables. TPSMD and TPS-FD failed to show statistically significant differences by participant sex ( $t$ $(79)=1.45, n s ; t(79)=1.68, n s$, respectively). This indicated that male participants did not differentially stick the female doll relative to the male doll (i.e., to indicate partner-directed aggression versus same-sex peer aggression) and, similarly, female participants did not differentially stick the male doll relative to the female doll. As there were no significant differences observed in pin sticking behavior by participant 
sex toward the male or female dolls, the TPS-MD and TPS-FD scores were summed to provide the Total Pin Sticks Overall (TPS-O) outcome variable for the present analyses. In four cases, pin stick data were only available from a single rater; in those cases, the available ratings from the single rater became the values for TPS-MD and TPS-FD. Table 5 provides mean comparisons between those in the ATSS provocation and the neutral conditions. Statistically significant differences were observed between ATSS conditions, with those in the provocation condition using the pins with the male doll, female doll, and overall relative to those in the neutral condition, $t(79)=2.52, p<$ $.05 ; t(79)=2.46, p<.05 ; t(79)=2.60, p<.05$, respectively.

\section{ATSS Aggression Variables}

Trained undergraduate RAs transcribed the ATSS audio for each participant into text documents. Then, separate trained undergraduate RAs coded the transcriptions for the frequency of statements uttered by the participants during their randomly assigned relationship jealousy or neutral ATSS scenario. The raters provided frequency counts for physically aggressive (i.e., statements indicating the intent to physically harm a character depicted in the relationship scenario) and verbally aggressive statements (i.e., statements with content intended to intimidate, demean, derogate, or insult a character depicted in the relationship scenario). These frequency scores became the ATSS Physical Aggression toward Partner (PA-P), Verbal Aggression toward Partner (VA-P), Physical Aggression toward Other (PA-O), and Verbal Aggression toward Other (VA-O) outcome variables. Dual coding for ATSS variables was available for $42 \%(n=34)$ of the sample. Intraclass correlation coefficient analysis indicated that inter-rater agreement for ATSS PA-P $(\alpha=.67)$ was 
low. The same inter-rater reliability analyses showed ATSS VA-P $(\alpha=.24)$, PA-O $(\alpha$ $=.17)$, and VA-O $(\alpha=.09)$ to be very low. As these reliabilities were unacceptable, the ATSS behavioral aggression variables were excluded from the analyses.

\section{Desired Behavior Inventory Aggression Variables}

Table 5 provides mean comparisons between those in the ATSS provocation and the neutral conditions in terms of the DBI variables. There were significant group differences on the DBI-PA and DBI-VA scales, such that those in the provocation condition expressed stronger desires to engage in physically and verbally aggressive behaviors during the ATSS scenario compared to those in the neutral condition ( $t$ (79) $=4.36, p<.01 ; t(79)=6.45, p<.01$, respectively).

\section{IPV History and Implicit Violence Attitudes}

To test the hypothesis that individuals with a history of physical IPV perpetration would show a greater IAT effect represented by a relatively lower mean V-IAT $D$ score, bivariate correlations were examined for these variables. The hypothesis was not supported, as V-IAT D scores were unrelated to physical IPV history (see Table 4). In order to compare mean differences in V-IAT D scores for participants with a self-reported history of physical IPV perpetration compared to those without in the current sample with the sample obtained by Eckhardt et al. (2012) and independent samples $t$-test was conducted. The mean differences across physical IPV perpetration history observed in the present sample and from Eckhardt et al. (2012) are available in Table 6 for comparison. Relative to the findings of Eckhardt and colleagues, the present results suggest that significant differences in implicit associations related to violence do not emerge in a non-clinical sample of 
undergraduate students with a history of infrequent physical IPV compared to those without.

\section{Attitudes Toward the Use of Violence as Moderation}

\section{TPS-O}

Multiple linear regression was used to test the hypothesis that implicit and explicit attitudes toward the use of violence together moderate the relationship between provocation and behavioral aggression. Total pin sticks (TPS-O) were regressed on the ATSS provocation condition contrast (Jealousy $=1$; Neutral $=-1)$, V-IAT $D$ scores, the Explicit Violence Attitudes composite in the first step, the two-way interaction terms in the second, and the three way ATSS provocation condition $x$ V-IAT score $x$ Explicit Violence Attitudes composite in the third step. The regression equation for the main

effects model failed to reach statistical significance, $R^{2}=.08, F(3,77)=2.32, p<.09$. Similarly, the models containing the 2-way and 3-way interactions failed to reach significance $\left(R^{2}=.09, F(6,74)=1.22, n s ; R^{2}=.10, F(7,73)=1.14, n s\right.$, respectively $)$.

\section{DBI}

The analysis was repeated with the DBI Physical Aggression as the outcome variable. Information regarding this sequential regression analysis is available in Table 7. The regression equation for the main effects model was statistically significant, $R^{2}=$ $.33, F(3,77)=12.33, p<.01$. The ATSS provocation condition contrast variable was significant, indicating that those in the provocation condition expressed a greater desire to engage in physical aggression while listening to the scenario compared to those in the neutral condition, $\beta=0.49, t(77)=5.13, p<.01$. The Explicit Violence Attitudes composite was also significant, $\beta=0.36, t(77)=3.86, p<.01$. The V-IAT $D$ scores 
failed to show main effects in the prediction of DBI-PA, $\beta<-0.01, t(77)=0.03$, ns. The equation for the second model was significant, $R^{2}=.41, F(6,74)=8.61, p<.01$. The ATSS provocation condition contrast by Explicit Violence Attitudes composite was significant and positive, indicating that the relationship between the ATSS provocation and DBI Physical Aggression is moderated by the degree to which one self-reports favorable attitudes related to violence, $\beta=0.30, t(74)=3.28, p<.01$. More specifically, for every standard unit increase in self-reported positive evaluations of violence, the strength of the relationship between provocation and the desire to physically aggress increases as well. Both the ATSS condition contrast by V-IAT score and the V-IAT score by Explicit Violence Attitudes composite interaction failed to reach significance $(\beta=-0.01, t(74)=.13, n s ; \beta=0.05, t(74)=0.51, n s$, respectively $)$. The equation for the full model was significant, $R^{2}=.41, F(7,73)=7.32, p<.01$. The addition of the ATSS provocation condition contrast $\mathrm{x}$ V-IAT score $\mathrm{x}$ Explicit Violence Attitudes Composite did not produce a significant contribution to accounting for variance in DBI-PA, $R^{2} \Delta<.01, n s$.

The analysis was repeated with the DBI Verbal Aggression as the outcome variable. The regression equation for the main effects model was statistically significant, $R^{2}=.43, F(3,77)=19.48, p<.01$. The ATSS provocation condition contrast variable was significant, indicating that those in the provocation condition expressed a greater mean desire to engage in verbally aggressive behavior while listening to the scenario compared to those in the neutral condition, $\beta=0.62, t(77)=$ 7.13, $p<.01$. The Explicit Violence Attitudes composite was also significant, $\beta=$ $0.28, t(77)=3.18, p<.01$. The V-IAT $D$ scores failed to show main effects in the 
prediction of DBI-VA, $\beta=-0.11, t(77)=1.36, n s$. The equation for the second model was significant but the addition of the 2-way interaction terms failed to produce a significant contribution toward predicting DBI-VA, $R^{2}=.46, F(6,74)=10.48, p<.01$, $R^{2} \Delta=.03$, ns. The equation for the full model was significant, $R^{2}=.47, F(7,73)=$ $9.29, p<.01$. The addition of the ATSS provocation condition contrast $x$ V-IAT score $\mathrm{x}$ Explicit Violence Attitudes Composite did not produce a significant contribution to accounting for variance in DBI-VA, $R^{2} \Delta=.01, n s$.

\section{Incremental Contribution of V-IAT D scores}

\section{TPS-O}

In order to test the hypothesis that V-IAT D scores provide an incremental contribution toward the prediction of aggressive behavior in the laboratory, sequential linear regression was utilized. TPS-O were regressed on the Explicit Violence Attitudes composite in the first step, and V-IAT D scores were added in the second step. The equation for the model containing the Explicit Violence Attitudes composite failed to show statistical significance, $R^{2}<.01, F(1,79)=0.95$, ns. The second equation containing both the Explicit Violence Attitudes composite and VIAT scores also failed to show statistical significance, $R^{2}<.01, F(2,78)=.94$, $n s$.

\section{DBI}

DBI Physical Aggression was regressed onto the Explicit Violence Attitudes composite in the first step and V-IAT $D$ scores were added in the second step. The regression equation for the first step was statistically significant, $R^{2}=.09, F(1,79)=$ $8.11, p<.01$. The Explicit Violence Attitudes composite was significantly predictive of DBI-PA such that those participants who self-report more positive beliefs regarding 
the use of violence in relationship contexts express a greater desire to be physically aggressive during simulated relationship scenarios, $\beta=0.31, t(79)=2.85, p<.01$. The equation for the full model with the addition of V-IAT $D$ scores was significant, $R^{2}=$ $.09, F(2,78)=4.01, p<.05$. The Explicit Violence Attitudes composite remained significant, $\beta=0.31, t(78)=2.85, p<.01 . \mathrm{V}$-IAT $D$ scores failed to reach statistical significance, $\beta=-0.01, t(78)=0.12$, ns. This suggests that V-IAT $D$ scores do not provide an incremental contribution toward the prediction of the desire to behave aggressively in a physical manner. The analyses were repeated with DBI Verbal Aggression as the outcome variable. The regression equation containing the Explicit Violence Attitudes composite alone approached significance, $R^{2}=.04, F(1,79)=3.20$, $p<.08$. The full model with V-IAT $D$ scores did not approach significance, $R^{2}=.01$, $F(2,78)=0.54, n s$.

To test whether implicit attitudes were able to predict behavioral aggression without explicit attitudes in the model, DBI-PA was regressed on centered V-IAT D scores. The equation for the regression failed to achieve statistical significance, $R^{2}<$ $.00, F(1,79)<0.00, n s$. The same analysis was conducted with DBI-VA as the outcome variable. Again, this regression equation failed to reach statistical significance, $R^{2}=.02, F(1,79)=1.27, n s$. The results suggest that V-IAT $D$ scores are not predictive of desire to engage in physical or verbal aggression during simulated relationship scenarios in a laboratory. 


\section{DISCUSSION}

The present study examined implicit and explicit attitudes toward the use of violence and their capacity to predict past and future partner-directed aggression in a nonclinical sample. Implicit attitudes were measured using a Violence-IAT and a battery of commonly used explicit self-report measures was used to index explicit violence attitudes prior to engaging in the ATSS anger induction paradigm. Participants were randomly assigned to listen to and imagine either a provocative or non-provocative relationship scenario and then had the opportunity to stick pins in dolls representing characters depicted in the scenarios. At the same time, participants were asked to "think out loud" about their thoughts, feelings, and reactions experienced during the scenario. Immediately after the scenario, participants were provided with a list of physically aggressive, verbally aggressive, and non-aggressive behaviors and asked to indicate the degree to which they would have liked to engage in each behavior while listening to their assigned relationship scenario. Implicit violence attitudes were significantly related to a history of IPV in the expected direction, but explicit violence attitudes were the only significant predictors of laboratory behavioral aggression.

Implicit violence attitudes were hypothesized to be related to self-reported IPV history such that individuals exhibiting a history of physical IPV acts in the past year would show a significantly greater IAT effect (i.e., a stronger association between 
violence and "good") indicating implicit attitudes relatively favoring the use of violence. The results of the current study did not support this hypothesis, as V-IAT $D$ scores were not significantly related to the variety of self-reported physically aggressive IPV acts perpetrated in the past 12 months. V-IAT $D$ scores were significantly correlated, however, to the variety of psychologically aggressive IPV acts in the past 12 months (e.g., Table 4). The observed relationship indicated that individuals who perpetrated more acts of psychological aggression against their partner tended to show a greater IAT effect and more closely associated 'violence' with 'good' in their minds. As shown in Table 3, psychological partner-directed aggression on the CTS2 displayed the highest mean value for the sample. Table 3 also shows that the mean variety of physically aggressive acts perpetrated in the past 12 months was less than one, indicating that physical aggression against a partner is relatively more infrequent in a non-clinical sample. Self-reported explicit violence attitudes, as indexed by the AVQ Total and the JVCT Total Verbal Aggression scores, were shown to be significantly positively related to a recent history of physical IPV perpetration (e.g., Table 4). These findings may indicate that psychological aggression is the most common form of IPV relative to physical IPV in a non-clinical sample and represent the terminal point for 'typical' relationship conflict (e.g., shouting, insults, etc.). If implicit violence attitudes are activated automatically in relevant relationship contexts, psychologically aggressive expression may represent an automatic, impulsive response to the instigation while physical aggression may be a relatively more controlled behavioral response and better represented by explicit violence attitudes. 
Implicit and explicit violence attitudes were expected to moderate the relationship between relationship provocation and behavioral aggression. Two measures of behavioral aggression were successfully employed to assess the degree to which levels of violence attitudes influence that provocation-aggression relationship. The current investigation supported this hypothesis and showed explicit attitudes to significantly interact with relationship provocation. More specifically, for those exposed to the relationship provocation scenario, a greater desire to engage in physically aggressive behavior was expressed by those with relatively more positive self-reported explicit violence attitudes compared to those with less positive violence attitudes in the same provoking relationship context. This interaction may be conceptualized according to the process components of the $\mathrm{I}^{3}$ (pronounced I-cubed) metatheoretical model for IPV (Finkel \& Eckhardt, 2013). In this model, relationship provocation is a form of instigation, as exposure to a provoking relationship situation normatively evokes an urge to behave aggressively within an individual. Positive explicit violence attitudes act as an impellance and amplify the urge to aggress in response to exposure to the provoking situation. The significant process interaction between provocation (instigation) and explicit violence attitudes (impellance) indicates an "urge-readiness" whereby more favorable attitudes towards the use of violence increase the magnitude of influence that exposure to a provoking relationship context has on expressed intent to become physically aggressive.

Explicit self-reported violence attitudes were predictive of the desire to be verbally aggressive, regardless of relationship instigation condition. In contrast, physical behavioral aggression in the form of pin sticks in the dolls failed to be 
predicted by explicit or implicit violence attitudes. Continuing with the conceptualization of explicit violence attitudes as an impelling factor toward aggressive behavior, the ability of these attitudes to predict aggression without an instigating factor is inconsistent with the expectations of the $\mathrm{I}^{3}$ model. For impellances to exert their influence on aggression likelihood, a relevant instigating factor must be present in order to provide the situational 'spark' of an urge to aggress. The relationship between the explicit violence attitudes and aggressive expression on the DBI may be the result of methodological overlap and this idea is discussed in the limitations section below. Implicit attitudes were hypothesized to provide an incremental contribution toward the prediction of behavioral aggression because of implicit attitudes' resistance to social desirability, regardless of relationship instigation. The current investigation did not support this hypothesis. Explicit violence attitudes significantly predicted the desire to engage in physically aggressive behaviors on the DBI. Implicit violence attitudes, as indexed by V-IAT $D$ scores, failed to provide an incremental contribution toward the prediction of this behavioral aggression outcome across relationship context. Even when V-IAT scores were entered alone as a predictor of the behavioral aggression outcomes, they failed to achieve statistical significance. Explicit and implicit violence attitudes were not predictive of doll pin sticks and DBI Verbal aggression. These results suggest that self-reports of explicit attitudes may provide more information regarding the complex cognitive environment precipitating the decision to become physically violent. 


\section{Limitations}

The similarity in method between explicit self-reports indexing violence attitudes and the DBI is important to keep in mind when evaluating the current results. The DBI is retrospective (i.e., the DBI is administered in questionnaire form immediately after the complete ATSS scenario is finished). The similarity in method may have some inherent overlap that artificially raises their inter-correlation. Also, the DBI requires conscious evaluation of the desire to engage in each of the behaviors listed. As such, it is impossible to capture impulsive aggressive responses to situational relationship provocation with this outcome measure. The DBI is also a new questionnaire that was developed for use in the current study. It currently lacks normative data to evaluate aggressive responding in isolation, without following both the ATSS response periods and the Voodoo Doll Task. This will need to be explored further in future investigations.

The current investigation was the first to divide the Voodoo Doll Task into male and female dolls. While the majority of the validation studies utilized a computerized version of the task in which a single, non-gendered dolls was stuck with a participant-selected number of pins, this modification was chosen in order to track partner-directed versus same-sex peer-directed aggression during the ATSS scenarios

using physical dolls as a lesser-removed analogue for behavioral aggression. However, several participants made statements about how the dolls with gender-stereotypical clothing were "off-putting", "weird", or that they "made [the participant] nervous." Only $35 \%(n=28)$ of participants stuck the dolls with the pins, suggesting that this method of having two dolls with gender-stereotypical clothing may not have 
been effective as an analogue for partner directed aggression in the laboratory, as too few of the present sample used the dolls to permit analysis in this way. Future investigations may have to modify the dolls, manipulating the manner in which the appearances of the dolls indicate the male and female options (e.g., with a label instead of clothing), so that participants are better able to use the dolls for the task.

The ATSS aggression variables could not be used in the current study. The ATSS offers an on-line assessment of cognitive and affective experience through 30second "think out loud" periods. As such, the ATSS may better capture aggressive intent through impulsive, spontaneous verbalizations that arise during affective arousal that may otherwise be missed by measures of more controlled behaviors (e.g., pin sticks or DBI reports of desired behaviors). Dual-coding of the ATSS aggression variables is crucial. The inter-rater agreement was unacceptable at the time of analysis and these variables could not be used in testing the hypotheses. As the ATSS aggression variables are missing from the analyses, it is currently not possible to determine whether V-IAT $D$ scores predict impulsive aggressive verbalizations, given the significant relationship that V-IAT D scores share with prior psychological IPV perpetration.

Participants were also asked to "think out loud" during the ATSS response periods and simultaneously with the Voodoo Doll Task. Some participants were observed to become completely absorbed in one task or the other (either responding during the ATSS response periods with what they were thinking regarding the scenario or deciding where and how many pins to place in each gendered doll) and state afterwards that they had forgotten about the other task. The failure to observe 
moderation for implicit and explicit violence attitudes on behavioral aggression as assessed by the ATSS verbalizations and doll pin sticks may be a matter of asking too much of the executive resources of the participants in the study. Prior investigations indexing ATSS verbalizations have made the task the sole activity for participants at the time of measurement (e.g., Eckhardt, 2007). Similarly, investigations utilizing the Voodoo Doll Task made it the sole focus during the time of aggression measurement (e.g., DeWall et al., 2013). As such, this design feature may represent a limitation of the current study. It is worth revisiting these real-time aggression paradigms individually in future investigations of the predictive ability of violence attitudes on partner-directed aggression.

The procedure of the current investigation required participants to complete the outcome measures in the same sequence (i.e., the ATSS 30s response periods simultaneously with the doll pin sticks, followed by the DBI questionnaire when the ATSS scenario was complete). It may be possible that participant reactance may be an issue. It is possible that a participant's response to one outcome measure (e.g., sticking a doll with a pin) may influence how they respond to other outcome measures. This reactance may influence subsequent responding in a cathartic manner (e.g., sticking a doll with a pin brings some relief to the participant and they indicate a lower desire to engage in aggressive behavior later on the DBI than they would had they not pinned the doll) or in a manner of facilitation (e.g., sticking a doll increases the desire to behave aggressively as indicated on the DBI). Contradictory findings in the field of aggression research have failed to provide evidence supporting catharsis theory (e.g., Bushman, 2002; Masoudnia, 2009) and the procedure of the current investigation 
prevents controlled analysis of these effects. As such, the possible inter-dependence among outcome variables represents a limitation of the current study.

The current investigation showed a restricted range of responding on the outcome variables (e.g., Table 5). The restricted range of responses left little variance to be accounted for by the implicit and explicit violence attitudes measures. Explicit violence attitudes were the most consistent predictor of behavioral aggression as indexed by the available outcome measures. Aside from the limitation discussed above for possible methodological overlap with the DBI, the predictive performance of these measures behavioral aggression in the laboratory despite the underperformance of these measures in the literature suggests the need to examine the nature of the sample. The non-clinical sample for the present investigation consisted of male and female undergraduate college students. The individuals with an IPV history recruited by Eckhardt et al. (2012) and Eckhardt and Crane (in press) were men recruited from intimate partner violence intervention programs. The explicit violence attitudes measures used by Eckhardt and colleagues were unable to distinguish between partnerviolent and nonviolent community controls. Considering prior research regarding the tendency of partner-violent individuals to minimize the extent of their violence and downplay their involvement in IPV perpetration (e.g., Archer, 2002; Ryan, 2013), it is probable that the partner-violent men recruited from the intervention programs may not fully indicate the extent to which they hold positive attitudes regarding the use of violence on explicit self-report measures. As such, their responses on these measures of violence attitudes may differ greatly from their actual endorsement of these beliefs. The break between reported and actual violence attitudes may be motivated by a fear of 
possible consequences for responses that more closely match the perpetrator's true attitudes. An alternative explanation may be that messages of non-violence from batterer intervention programming are salient in the minds of recruited IPV perpetrators and contribute to the incongruity between reported and actual violence attitudes. The discrepancy between what a clinical IPV sample reports and their actual behavior may present a greater opportunity for implicit violence attitudes to account for variance in aggression responding. Relative to a clinical IPV sample, the present nonclinical sample may feel less of a need to misrepresent the extent to which they consciously believe violence to be a justified and effective solution to relationship conflict. If this is the case, there may be little discrepancy between their reported attitudes regarding the use of violence and their behavioral aggression. With less of a discrepancy, the explicit attitudes measures may better account for and predict behavioral aggression in this sample and present less of an opportunity for implicit violence attitudes to show a contribution. It may be that, for an 'honest' sample (e.g., non-clinical with little to gain by misrepresenting themselves), implicit associations between 'violence' and 'good' represent learned associations from repeated exposure to relationship conflict and repetitive urges to aggress against a partner (e.g., interpersonal models of IPV; Finkel \& Eckhardt, 2013). The aggressive urges, however, are likely inhibited by any of a number of presently unmeasured factors that contribute to the non-clinical status of the sample. Though, for individuals with explicit attitudes favoring the use of violence, the desire to inhibit aggressive urges may be unlikely in the context of relationship provocation and these urges become expressed as behavioral aggression. 


\section{Conclusion}

The present study is the first to recruit a nonclinical sample to examine the predictive ability of V-IAT $D$ scores on aggressive behavior in a controlled laboratory setting. Eckhardt et al. (2012) found that V-IAT D scores were able to significantly differentiate between a clinical sample of IPV perpetrators in an intimate partner violence intervention program and a comparison community sample of nonviolent men. The sample for the current study consisted entirely of college undergraduate students. V-IAT D scores were unrelated to a recent history of self-reported physical partner violence perpetration. However, V-IAT D scores were significantly related to self-reported psychological IPV perpetration which suggests that people with relatively more positive implicit attitudes related to violence tend to perpetrate a greater variety of psychologically aggressive acts against their partners. It is important to note that the sample as a whole tended to have negative views toward the use of violence and showed delays on the incongruent trials of the V-IAT. The V-IAT D scores are not intended to be a diagnostic measure for partner violent individuals and replace explicit means of indexing the construct (Nosek, 2005). Rather, future research is needed to explore the contribution of V-IAT D scores toward predicting hypothetical and actual behavior in real social situations. As noted by Eckhardt and colleagues, a combined approach to assessing violence attitudes may yield information regarding both conscious and unconscious associations in a given relationship context and explicit self-reports may indicate the result of complex cognitive frameworks for how these automatic associations are interpreted for a person. 
In summary, the results of the current investigation generally support previous findings (i.e., Eckhardt et al., 2012) that implicit violence attitudes measured with a Violence IAT are able to distinguish between individuals with and without a history of psychological IPV. Implicit violence attitudes were unable to distinguish those who perpetrated physical IPV from those who had not, however. Explicit self-reported violence attitudes were shown to interact with provocative relationship scenarios, indicating greater behavioral aggressive responses for individuals exposed to relationship-relevant instigation who have more favorable evaluations regarding the use of violence compared to individuals with less favorable violence attitudes in the same social situation. Implicit violence attitudes were not shown to be significant predictors of behavioral aggression in a controlled laboratory setting. Future studies should continue to explore the boundaries of application for implicit violence attitudes. The current study was unable to replicate the mean differences in Violence IAT scores for non-clinical individuals with and without a history of physical violence as had been observed in Eckhardt et al. (2012), but observed a similar pattern with a history of psychological IPV perpetration. Future prospective investigations should explore the predictive ability of these implicit and explicit violence attitudes for a clinical sample in a controlled laboratory setting in order to better understand the populations for which they more reliably predict physical behavioral aggression in the moment. The current investigation lends support to the body of literature conceptualizing violence attitudes as contributing factors toward partner-directed aggression. Continued efforts are warranted in order to better understand for whom these attitudes matter most, in 
which situations, and what behaviors they reliably indicate for obvious clinical and research purposes. 


\section{NOTES}

1. The unequal number of members across the randomly-assigned ATSS conditions was due to an error in the computer program for the non-provocation scenario of the ATSS. Independent samples $t$-tests were conducted on the explicit and implicit attitudes across ATSS condition to ensure equivalence in these factors across groups. The table showing the results of these tests (see Appendix B) indicates that only 2 subscales of 12 showed significant mean differences by condition, but these subscales were not incorporated in the analyses so parity across group assignment is assumed.

2. Participants who endorsed a non-heterosexual preference were excluded because of the heterosexual nature of the characters depicted in the relationship stimuli in the Articulated Thoughts in Simulated Situations paradigm.

3. Filler questionnaires indexing positive or unrelated constructs (e.g., the tendency to become lost in daydreams) were interspersed throughout the explicit violence attitudes battery. This was done for the purpose of avoiding possible violence priming effects from answering 68 items regarding the justification and effectiveness of violent behavior. 
LIST OF REFERENCES 


\section{LIST OF REFERENCES}

Albarracín, D., \& Wyer, R. S., Jr. (2000). The cognitive impact of past behavior: Influences on beliefs, attitudes, and future behavioral decisions. Journal of Personality and Social Psychology, 79(1), 5-22. doi: 10.1037/0022-3514.79.1.5

Andrews, D. A., \& Bonta, J. (2010). Rehabilitating criminal justice policy and practice. Psychology, Public Policy, and Law, 16(1), 39-55. doi: 10.1037/a0018362

Anglin, K., \& Holtzworth-Munroe, A. (1997). Comparing the responses of maritally violent and nonviolent spouses to problematic marital and nonmarital situations: Are the skill deficits of physically aggressive husbands and wives global? Journal of Family Psychology, 11(3), 301-313. doi: 10.1037/08933200.11.3.301

Archer, J. (2002). Sex differences in physically aggressive acts between heterosexual partners: A meta-analytic review. Aggression and Violent Behavior, 7, 313-351.

Ayres, K., Conner, M. T., Prestwich, A., \& Smith, P. (2012). Do implicit measures of attitudes incrementally predict snacking behaviour over explicit affect-related measures? Appetite, 58(3), 835-841. doi: 10.1016/j.appet.2012.01.019

Bushman, B. J. (2002). Does venting anger feed or extinguish the flame? Catharsis, rumination, distraction, anger and aggressive responding. Personality and Social Psychology Bulletin, 28(6), 724-731. doi: 10.1177/0146167202289002 
Davison, G. C., Robins, C., \& Johnson, M. K. (1983). Articulated thoughts during simulated situations: A paradigm for studying cognition in emotion and behavior. Cognitive Therapy and Research, 7(1), 17-39. doi:

10.1007/BF01173421

DeWall, C. N., Finkel, E. J., Lambert, N. M., Slotter, E. B., Bodenhausen, G. V., Pond, R. S., . . Fincham, F. D. (2013). The voodoo doll task: Introducing and validating a novel method for studying aggressive inclinations. Aggressive Behavior, 39(6), 419-439. doi: 10.1002/ab.21496

Eckhardt, C., Barbour, K. A., \& Davison, G. C. (1998). Articulated thoughts of maritally violent and nonviolent men during anger arousal. Journal of Consulting \& Clinical Psychology, 66(2), 259-269.

Eckhardt, C., \& Jamison, T. R. (2002). Articulated thoughts of male dating violence perpetrators during anger arousal. Cognitive Therapy \& Research, 26(3), 289308.

Eckhardt, C. I., Barbour, K. A., \& Davison, G. C. (1998). Articulated thoughts of maritally violent and nonviolent men during anger arousal. Journal of Consulting and Clinical Psychology, 66(2), 259-269.

Eckhardt, C., \& Crane, C. (in press). Male perpetrators of intimate partner violence and implicit attitudes toward violence: Associations with treatment outcomes. Cognitive Therapy and Research.

Eckhardt, C. I., \& Dye, M. L. (2000). The cognitive characteristics of maritally violent men: Theory and evidence. Cognitive Therapy and Research, 24(2), 139-158. doi: 10.1023/A:1005441924292 
Eckhardt, C. I., Samper, R., Suhr, L., \& Holtzworth-Munroe, A. (2012). Implicit attitudes toward violence among male perpetrators of intimate partner violence: A preliminary investigation. Journal of Interpersonal Violence, 27(3), 471-491. doi: $10.1177 / 0886260511421677$

Faul, F., Erdfelder, E., Buchner, A., \& Lang, A. G. (2009). Statistical power analyses using $\mathrm{G}^{*}$ Power 3.1: Tests for correlation and regression analyses. Behavior Research Methods, 41, 1149-1160.

Fincham, F. D., Bradbury, T. N., Arias, I., Byrne, C. A., \& Karney, B. R. (1997). Marital violence, marital distress, and attributions. Journal of Family Psychology, 11(3), 367-372. doi: 10.1037/0893-3200.11.3.367

Finkel, E. J., \& Eckhardt, C. I. (2013). Intimate partner violence. In J. A. Simpson \& L. Campbell (Eds.), The Oxford handbook of close relationships (pp. 452-474). New York, NY: Oxford.

Fraley, R. C., \& Marks, M. J. (2007). The null hypothesis significance-testing debate and its implications for personality research. In R. W. Robins, R. C. Fraley \& R. F. Krueger (Eds.), Handbook of research methods in personality psychology (pp. 149-169). New York, NY: Guilford Press.

Glasman, L. R., \& Albarracin, D. (2006). Forming attitudes that predict future behavior: A meta-analysis of the attitude-behavior relation. Psychological Bulletin, 132(5), 778-822.

Golding, J. M. (1999). Sexual-assault history and long-term physical health problems: Evidence from clinical and population epidemiology. Current Directions in Psychological Science, 8(6), 191-194. doi: 10.1111/1467-8721.00045 
Gray, N. S., MacCulloch, M. J., Smith, J., Morris, M., \& Snowden, R. J. (2003). Violence viewed by psychopathic murderers: Adapting a revealing test may expose those psychopaths who are most likely to kill. Nature, 423(6939), 497498. doi: $10.1038 / 423497 \mathrm{a}$

Greenwald, A. G., Banaji, M. R., Rudman, L. A., Farnham, S. D., Nosek, B. A., \& Mellott, D. S. (2002). A unified theory of implicit attitudes, stereotypes, selfesteem, and self-concept. Psychological Review, 109(1), 3-25. doi: 10.1037//0033-295x.109.1.3

Greenwald, A. G., McGhee, D. E., \& Schwartz, J. L. K. (1998). Measuring individual differences in implicit cognition: The implicit association test. Journal of Personality and Social Psychology, 74(6), 1464-1480. doi: 10.1037/00223514.74.6.1464

Greenwald, A. G., Nosek, B. A., \& Banaji, M. R. (2003). Understanding and using the Implicit Association Test: I. An improved scoring algorithm. Journal of Personality and Social Psychology, 85(2), 197-216. doi: 10.1037/00223514.85 .2 .197

Greenwald, A. G., Poehlman, T. A., Uhlmann, E. L., \& Banaji, M. R. (2009). Understanding and using the Implicit Association Test: III. Meta-analysis of predictive validity. Journal of Personality and Social Psychology, 97(1), 17-41.

Grumm, M., Hein, S., \& Fingerle, M. (2011). Predicting aggressive behavior in children with the help of measures of implicit and explicit aggression. International Journal of Behavioral Development, 35(4), 352-357. doi: $10.1177 / 0165025411405955$ 
Jarvis, B. G., (2012). DirectRT (Version v. 2012.4) [computer software]. New York, NY: Empirisoft Corporation.

Jarvis, B. G., (2012). MediaLab (Version v. 2012.4) [computer software]. New York, NY: Empirisoft Corporation.

Jacobson, N. S. (1994). Rewards and dangers in researching domestic violence. Family Process, 33(1), 81-85. doi: 10.1111/j.1545-5300.1994.00081.x

Kelly, A., \& Barnes-Holmes, D. (2013). Implicit attitudes towards children with autism versus normally developing children as predictors of professional burnout and psychopathology. Research in Developmental Disabilities, 34(1), 17-28. doi: 10.1016/j.ridd.2012.07.018

Lawrence, E., Orengo-Aguayo, R., Langer, A., \& Brock, R. L. (2012). The impact and consequences of partner abuse on partners. Partner Abuse, 3(4), 406-428. doi: 10.1891/1946-6560.3.4.406

Marquardt, N., Gades, R., \& Robelski, S. (2012). Implicit social cognition and safety culture. Human Factors and Ergonomics in Manufacturing \& Service Industries, 22(3), 213-234. doi: 10.1002/hfm.20264

Masoudnia, E. (2009). Aggression and anti-social behavioral in adolescents: An appraisal of catharsis of aggression theory. Journal of Psychology, 13(2), 138152.

Mierke, J., \& Klauer, K. C. (2003). Method-specific variance in the implicit association test. Journal of Personality and Social Psychology, 85(6), 1180-1192. doi:

$10.1037 / 0022-3514.85 .6 .1180$ 
Murphy, C. M. E. C. I. (2005). Treating the abusive partner: An individualized cognitive-behavioral approach. New York, NY: Guilford Press.

Nosek, B. A. (2005). Moderators of the relationship between implicit and explicit evaluation. Journal of Experimental Psychology: General, 134(4), 565-584. doi: $10.1037 / 0096-3445.134 .4 .565$

Paulhus, D. L., \& Vazire, S. (2007). The self-report method. In R. W. Robins, R. C. Fraley \& R. F. Krueger (Eds.), Handbook of research methods in personality psychology. (pp. 224-239). New York, NY: Guilford Press.

Pence, E., \& Paymar, M. (1993). Education groups for men who batter: The Duluth model. New York, NY: Springer Publishing Co.

Richetin, J., Richardson, D. S., \& Mason, G. (2010). Predictive validity of aggressiveness-IAT in the context of provocation. Social Psychology, 41, 2734.

Riggs, D. S., \& O'Leary, K. D. (1996). Aggression between heterosexual dating partners: An examination of a causal model of courtship aggression. Journal of Interpersonal Violence, 11(4), 519-540. doi: 10.1177/088626096011004005

Robertson, K., \& Murachver, T. (2007). Correlates of partner violence for incarcerated women and men. Journal of Interpersonal Violence, 22(5), 639-655. doi: $10.1177 / 0886260506298835$

Rudman, L. A., \& Ashmore, R. D. (2007). Discrimination and the Implicit Association Test. Group Processes \& Intergroup Relations, 10(3), 359-372. doi: $10.1177 / 1368430207078696$ 
Ryan, K. M. (2013). Issues of reliability in measuring intimate partner violence during courtship. Sex Roles, 69(3-4), 131-148. doi: 10.1007/s11199-012-0233-4

Scott, K., \& Straus, M. (2007). Denial, minimization, partner blaming, and intimate aggression in dating partners. Journal of Interpersonal Violence, 22(7), 851871. doi: 10.1177/0886260507301227

Scott, K., \& Straus, M. (2007). Denial, minimization, partner blaming, and intimate aggression in dating partners. Journal of Interpersonal Violence, 22, 851-871.

Slep, A. M., Cascardi, M., Avery-Leaf, S., \& O’Leary, K. D. (2001). Two measures of attitudes about the acceptability of teen dating aggression. Psychological Assessment, 13(3), 306-318.

Stith, S. M., Smith, D. B., Penn, C. E., Ward, D. B., \& Tritt, D. (2004). Intimate partner physical abuse perpetration and victimization risk factors: A metaanalytic review. Aggression and Violent Behavior, 10(1), 65-98. doi: 10.1016/j.avb.2003.09.001

Stith, S. M., Smith, D. B., Penn, C. E., Ward, D. B., \& Tritt, D. (2004). Intimate partner physical abuse perpetration and victimization risk factors: A metaanalytic review. Aggression and Violent Behavior, 10, 65-98.

Straus, M. A., Hamby, S. L., Boney-McCoy, S., \& Sugarman, D. B. (1996). The revised Conflict Tactics Scales (CTS2): Development and preliminary psychometric data. Journal of Family Issues, 17(3), 283-316. doi: $10.1177 / 019251396017003001$ 
Sugarman, D. B., \& Frankel, S. L. (1996). Patriarchal ideology and wife-assault: A meta-analytic review. Journal of Family Violence, 11(1), 13-40. doi: 10.1007/BF02333338

Sugarman, D. B., \& Hotaling, G. T. (1997). Intimate violence and social desirability: A meta-analytic review. Journal of Interpersonal Violence, 12(2), 275-290.

Todorov, A., \& Bargh, J. A. (2002). Automatic sources of aggression. Aggression and Violent Behavior, 7(1), 53-68. doi: 10.1016/S1359-1789(00)00036-7

van Goethem, A. A., Scholte, R. H., \& Wiers, R. W. (2010). Explicit- and implicit bullying attitudes in relation to bullying behavior. Journal of Abnormal Child Psychology, 38(6), 829-842. doi: 10.1007/s10802-010-9405-2 
APPENDICES 
Appendix A

Table 1

Demographic Data for Sample

Variable

Mean age $(S D)$

$19.23(1.24)$

Race/ethnicity (\%)

White

74.1

Asian

18.5

African American

4.9

American Indian or Alaska Native

2.5

Mean years of education (SD)

$14.30(1.44)$

Marital status (\%)

Single

97.5

Not married/living with partner

2.5 


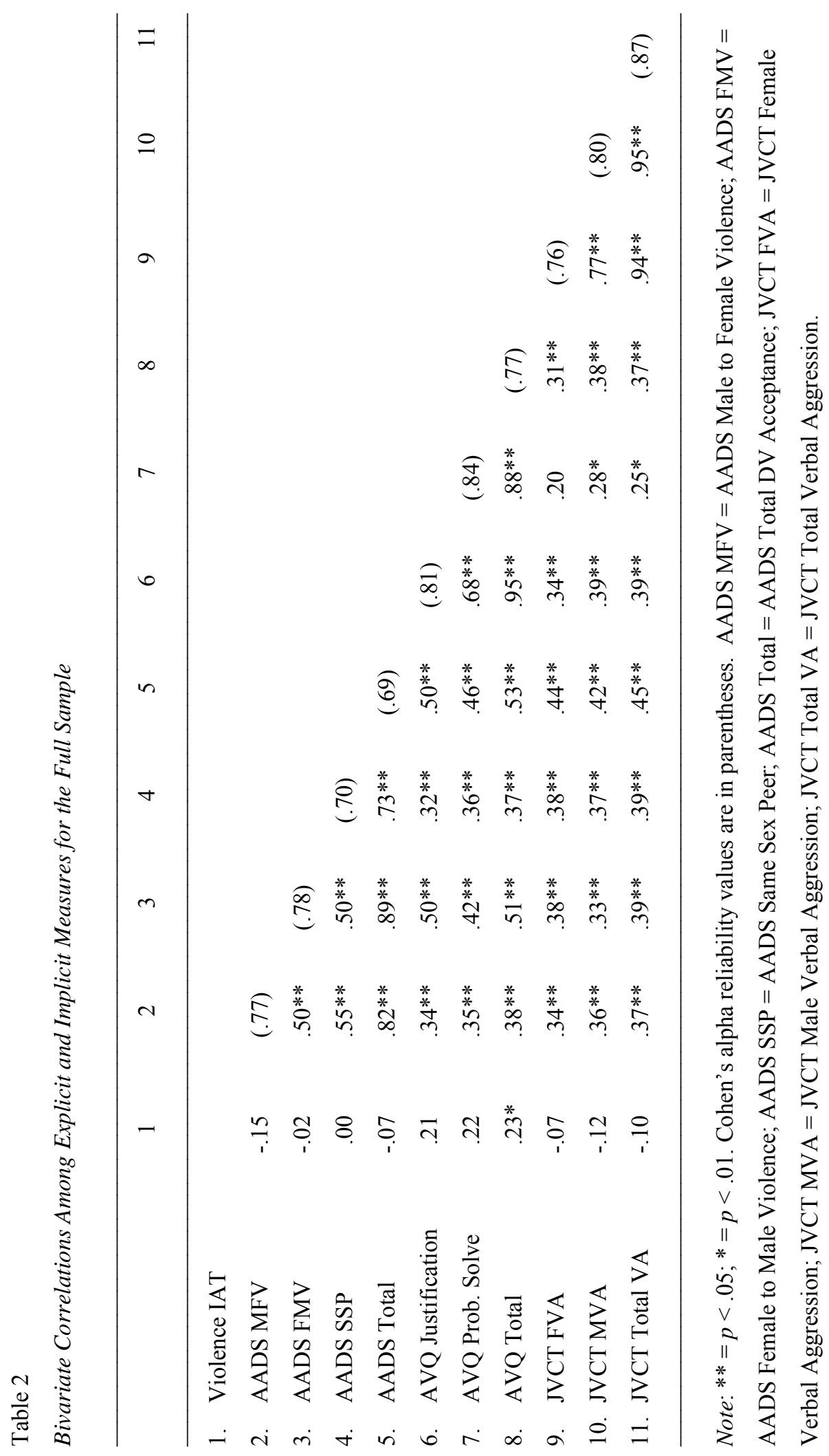


Table 3

CTS2 12-Month IPV Perpetration Values for the Full Sample

Variable

CTS2 IPV 12-mo. Perpetration History Yes/No (\%)

Physical Aggression

$35.6(n=28)$

Psychological Aggression

$86.4(n=70)$

Total Aggression

$86.4(n=70)$

CTS2 12 mo. Perpetration Variety Score Mean (SD)

Physical Aggression

Psychological Aggression

$0.75(1.37)$

Note. CTS = Revised Conflict Tactics Scale; Variety scoring of the CTS (e.g., Moffitt et al., 1997) indicates the number of different IPV acts, rather than the frequency of acts, perpetrated by the respondent in the past 12 months. 
Table 4

Bivariate Correlations Between Violence-IAT D Scores or Explicit Violence Attitudes Measures and CTS2 12-Month IPV Variety Scores

Psychological Aggression Physical Aggression

Violence-IAT Score

AADS Total DV Acceptance

AVQ Total Score

JVCT Total Verbal Aggression
$-.32 * *$

.06

.11

.45
.00

.21

$.33^{* *}$

$.45^{* *}$

Note. ${ }^{*} p<.05, * * p<.01$. AADS $=$ Attitudes about Aggression in Dating Situations Scale; AVQ $=$ Acceptance of Violence Questionnaire; JVCT $=$ Justification of Jealous and Coercive Tactics Scale. JVCT Total Verbal Aggression Score is the sum of female and male verbal aggression subscales. Lower Violence-IAT D Scores indicate an IAT effect, or a stronger implicit association between violence and positive evaluations. 


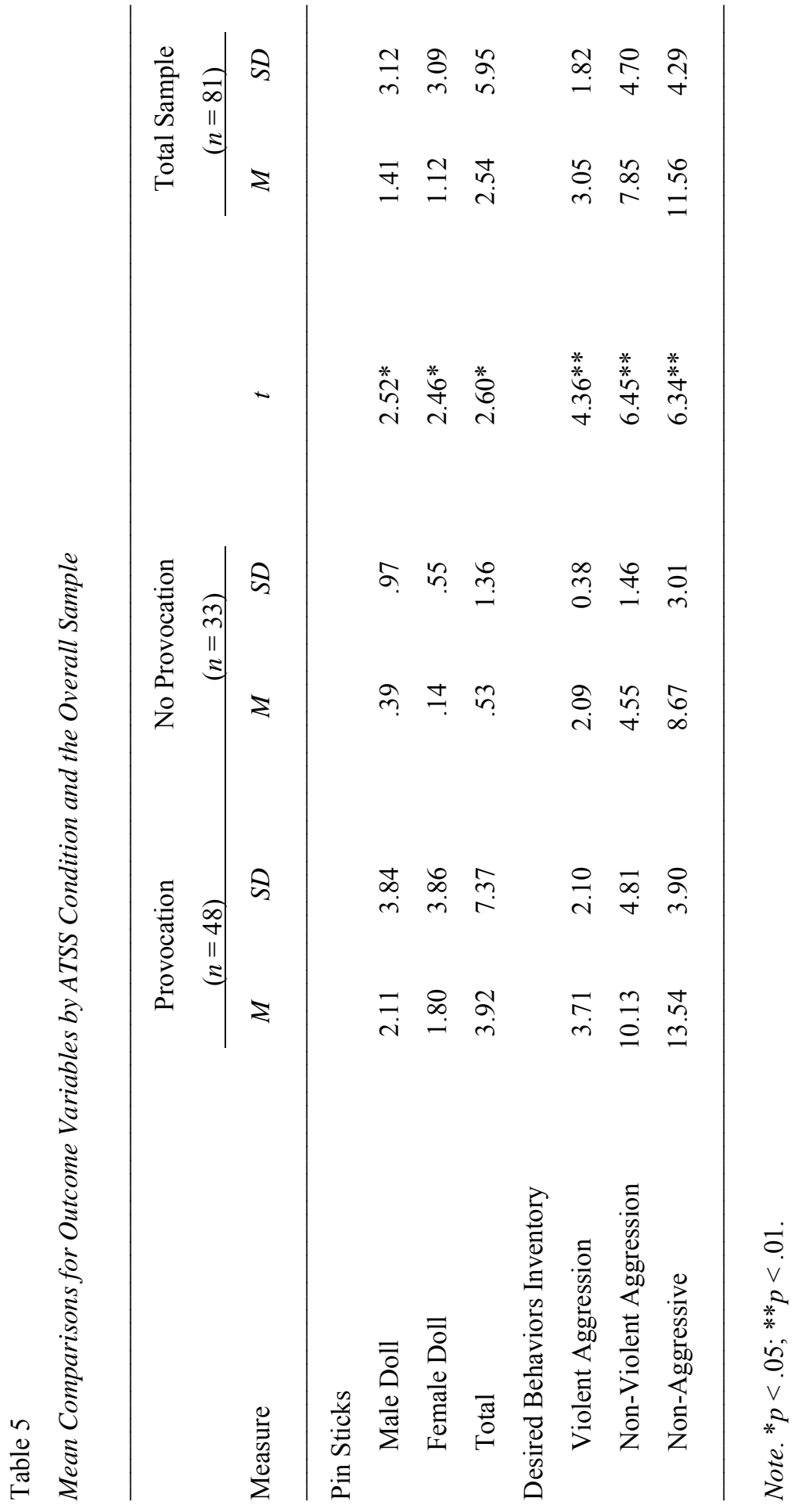


Table 6

Mean Violence IAT D Scores by CTS2 IPV History for Current Sample Compared to Eckhardt et al. (2012)

$\underline{\text { Violence IAT Score }}$

\begin{tabular}{lcccc} 
Study & $n$ & $M$ & $S D$ & $t$ \\
\hline $\begin{array}{l}\text { Current Sample } \\
\text { Physical IPV History }\end{array}$ & 28 & 0.96 & 0.40 & 0.10 \\
$\quad$ No Physical IPV History & 53 & 0.95 & 0.32 & \\
$\quad$ Total & 81 & 0.96 & 0.35 & \\
Eckhardt et al. (2012) & & & & \\
$\quad$ Physical IPV History & 50 & 1.15 & 0.33 & \\
No Physical IPV History & 40 & 1.28 & 0.17 & \\
$\quad$ Total & 90 & - & - & \\
\end{tabular}

Note. ${ }^{*} p<.05$. The participants with a history of physical partner violence in Eckhardt et al. (2012) were men recruited from an IPV treatment program and the nonviolent participants were men recruited from the community. The sample for the current study was a non-clinical sample that consisted of male and female undergraduate students from a large Midwestern university. 
Table 7

Sequential Regression Analyses With ATSS Provocation Condition Contrast, Explicit, and Implicit Attitudes Predicting DBI Violent Aggression

Predictors

B SE B

$\beta$

Sig.

Main Effects

$\begin{array}{lccccc}\text { Intercept } & 2.89 & 0.17 & & 16.77 & .000 \\ \text { Contrast } & 0.89 & 0.17 & 0.49 & 5.13 & .000 \\ \text { V-IAT } & -0.01 & 0.49 & -0.00 & -0.03 & n s \\ \text { EVA } & 0.83 & 0.22 & 0.36 & 3.56 & .00\end{array}$

Second Step

$\begin{array}{lccccc}\text { Intercept } & 2.95 & 0.17 & & 17.86 & .000 \\ \text { Contrast } & 0.88 & 0.17 & 0.48 & 5.35 & .000 \\ \text { V-IAT } & 0.04 & 0.49 & 0.01 & 0.08 & n s \\ \text { EVA } & 0.81 & 0.21 & 0.35 & 3.79 & .000 \\ \text { Contrast x V-IAT } & -0.06 & 0.47 & -0.01 & -0.13 & n s \\ \text { Contrast x EVA } & 0.70 & 0.21 & 0.30 & 3.28 & .002 \\ \text { V-IAT x EVA } & 0.35 & 0.69 & 0.05 & 0.51 & n s\end{array}$

Third Step

$\begin{array}{lrrrrr}\text { Intercept } & 2.95 & 0.17 & & 17.70 & .000 \\ \text { Contrast } & 0.89 & 0.17 & 0.48 & 5.32 & .000\end{array}$




\begin{tabular}{lccccc}
\hline Predictors & $B$ & SE B & $\beta$ & $t$ & Sig. \\
\hline V-IAT & 0.03 & 0.50 & 0.01 & 0.06 & $n s$ \\
EVA & 0.79 & 0.22 & 0.34 & 3.56 & .001 \\
Contrast x V-IAT & -0.12 & 0.50 & -0.02 & -0.25 & $n s$ \\
Contrast x EVA & 0.72 & 0.22 & 0.31 & 3.26 & .002 \\
V-IAT x EVA & 0.35 & 0.70 & 0.05 & 0.51 & $n s$ \\
$\quad$ Contrast x V-IAT x EVA & -0.29 & 0.70 & -0.04 & -0.41 & $n s$ \\
\end{tabular}

Note. Contrast $=$ ATSS Provocation Condition Contrast; EVA $=$ Explicit Violence Attitudes Composite; V-IAT = Violence IAT Scores. 


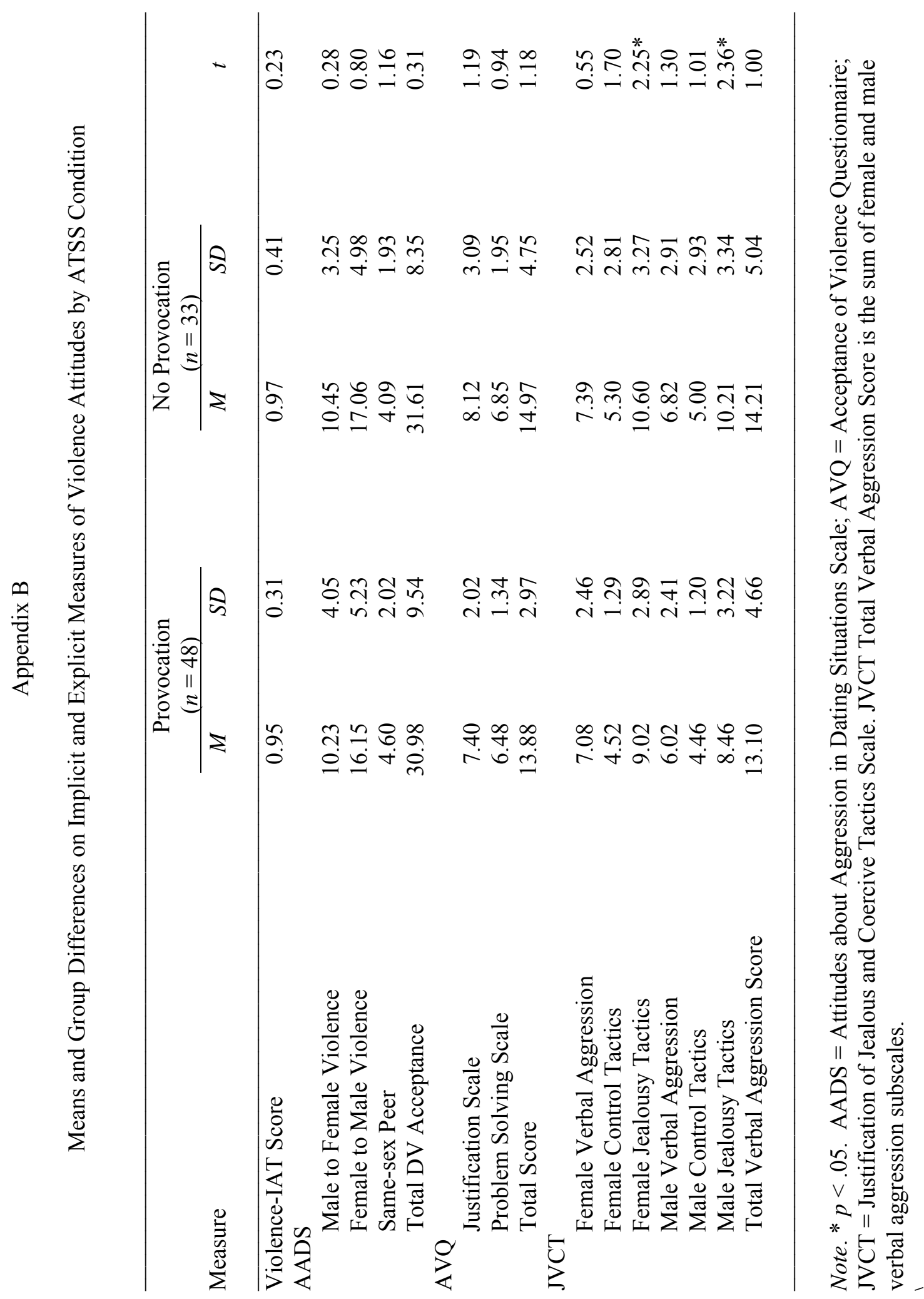




\section{Appendix C}

Items from the CTS2 (Straus, Hamby, Boney-McCoy, \& Sugarman, 1996)

CTS2 Psychological Aggression Scale Items

\begin{tabular}{|c|c|c|c|}
\hline Question \# & Subscale & Item & Rating \\
\hline 5 & Minor & I insulted or swore at my partner. & 12345670 \\
\hline 35 & Minor & I shouted or yelled at my partner. & 12345670 \\
\hline 49 & Minor & $\begin{array}{l}\text { I stomped out of the room or house or } \\
\text { yard during a disagreement. }\end{array}$ & 12345670 \\
\hline 67 & Minor & I did something to spite my partner. & 12345670 \\
\hline 25 & Severe & I called my partner fat or ugly. & 12345670 \\
\hline 29 & Severe & $\begin{array}{l}\text { I destroyed something belonging to my } \\
\text { Partner. }\end{array}$ & 12345670 \\
\hline 65 & Severe & I accused my partner of being a lousy lover. & 12345670 \\
\hline \multirow[t]{2}{*}{69} & Severe & $\begin{array}{l}\text { I threatened to hit or throw something at } \\
\text { my partner. }\end{array}$ & 12345670 \\
\hline & & CTS2 Physical Assault Scale Items & \\
\hline \multirow{2}{*}{$\begin{array}{c}\text { Question \# } \\
7\end{array}$} & Subscale & Item & Rating \\
\hline & Minor & $\begin{array}{l}\text { I threw something at my partner that could } \\
\text { hurt. }\end{array}$ & 12345670 \\
\hline 9 & Minor & I twisted my partner's arm or hair. & 12345670 \\
\hline 17 & Minor & I pushed or shoved my partner. & 12345670 \\
\hline 45 & Minor & I grabbed my partner. & 12345670 \\
\hline 53 & Minor & I slapped my partner. & 12345670 \\
\hline 21 & Severe & I used a knife or gun on my partner. & 12345670 \\
\hline 27 & Severe & $\begin{array}{l}\text { I punched or hit my partner with something } \\
\text { that could hurt. }\end{array}$ & 12345670 \\
\hline 33 & Severe & I choked my partner. & 12345670 \\
\hline 37 & Severe & I slammed my partner against a wall. & 12345670 \\
\hline 43 & Severe & I beat up my partner. & 12345670 \\
\hline 61 & Severe & I burned or scalded my partner on purpose. & 12345670 \\
\hline 73 & Severe & I kicked my partner. & 12345670 \\
\hline
\end{tabular}

\begin{tabular}{|l|l|}
\hline \multicolumn{2}{|c|}{ How often did this happen? } \\
\hline 1 & Once in the past year \\
\hline 2 & Twice in the past year \\
\hline 3 & $3-5$ times in the past year \\
\hline 4 & $6-10$ times in the past year \\
\hline 5 & $11-20$ times in the past year \\
\hline 6 & More than 20 times in the past year \\
\hline 7 & Not in the past year, but it did happen before \\
\hline 0 & This has never happened \\
\hline
\end{tabular}




\section{Appendix D}

Acceptance of Violence Questionnaire (AVQ; Riggs \& O’Leary, 1996)

Please answer each question below using the following scale:

\begin{tabular}{|c|c|c|c|}
\hline 0 & 1 & 2 & 3 \\
\hline Never & & & Always \\
\hline
\end{tabular}

1. If a man pushes his girlfriend during an argument, is it justified?

2. Will the man's pushing solve the problem between him and his girlfriend?

3. If a woman pushes her boyfriend during an argument, is it justified?

4. Will the woman's pushing solve the problem between her and her boyfriend?

5. If a man slaps his girlfriend during an argument, is it justified?

6. Will the man's slapping solve the problem between him and his girlfriend?

7. If a woman slaps her boyfriend during an argument, is it justified?

8. Will the woman's slapping solve the problem between her and her boyfriend?

9. If a man punches his girlfriend during an argument, is it justified?

10. Will the man's punching solve the problem between him and his girlfriend?

11. If a woman punches her boyfriend during an argument, is it justified?

12. Will the woman's punching solve the problem between her and her boyfriend?

Justification: Items 1, 3, 5, 7, 9, 11

Problem Solution: Items 2, 4, 6, 8, 10, 12 
Appendix E

Desired Behaviors Inventory - Provocation (DBI-P)

The following is a list of actions that you may wish to perform at this moment, but are not possible at this time. Please use the scale provided below to indicate, if you had the chance right now, how much you would like to do each of the following actions after listening to the relationship scenario.

\begin{tabular}{ccccc} 
Not At All & \multicolumn{3}{c}{ Maybe } & Very Much \\
1 & 2 & 3 & 4 & 5
\end{tabular}

After listening to the scenario, how much would you like to...

1. Take a walk

2. Hit your partner

3. Drive home

4. Hit the intruder

5. Call a friend

6. Shout at your partner

7. Go out with your friends

8. Shout at the intruder

9. Threaten the intruder

10. Threaten your partner

Physical Aggression: $2+4$

Verbal Aggression: $6+8+9+10$

Non-Aggressive: $1+3+5+7$ 
The following is a list of actions that you may wish to perform at this moment, but are not possible at this time. Please use the scale provided below to indicate, if you had the chance right now, how much you would like to do each of the following actions after listening to the relationship scenario.

\begin{tabular}{ccccc} 
Not At All & \multicolumn{3}{c}{ Maybe } & Very Much \\
1 & 2 & 3 & 4 & 5
\end{tabular}

After listening to the scenario, how much would you like to...

1. Take a walk

2. Hit the man at the next table

3. Drive home

4. Hit the woman at the next table

5. Call a friend

6. Shout at your partner when he/she arrives

7. Go out with your friends

8. Shout at the couple at the next table

9. Threaten the couple at the next table

10. Threaten your partner when he/she arrives

Physical Aggression: $2+4$

Verbal Aggression: $6+8+9+10$

Non-Aggressive: $1+3+5+7$ 
Appendix F

Experimental Lab Room

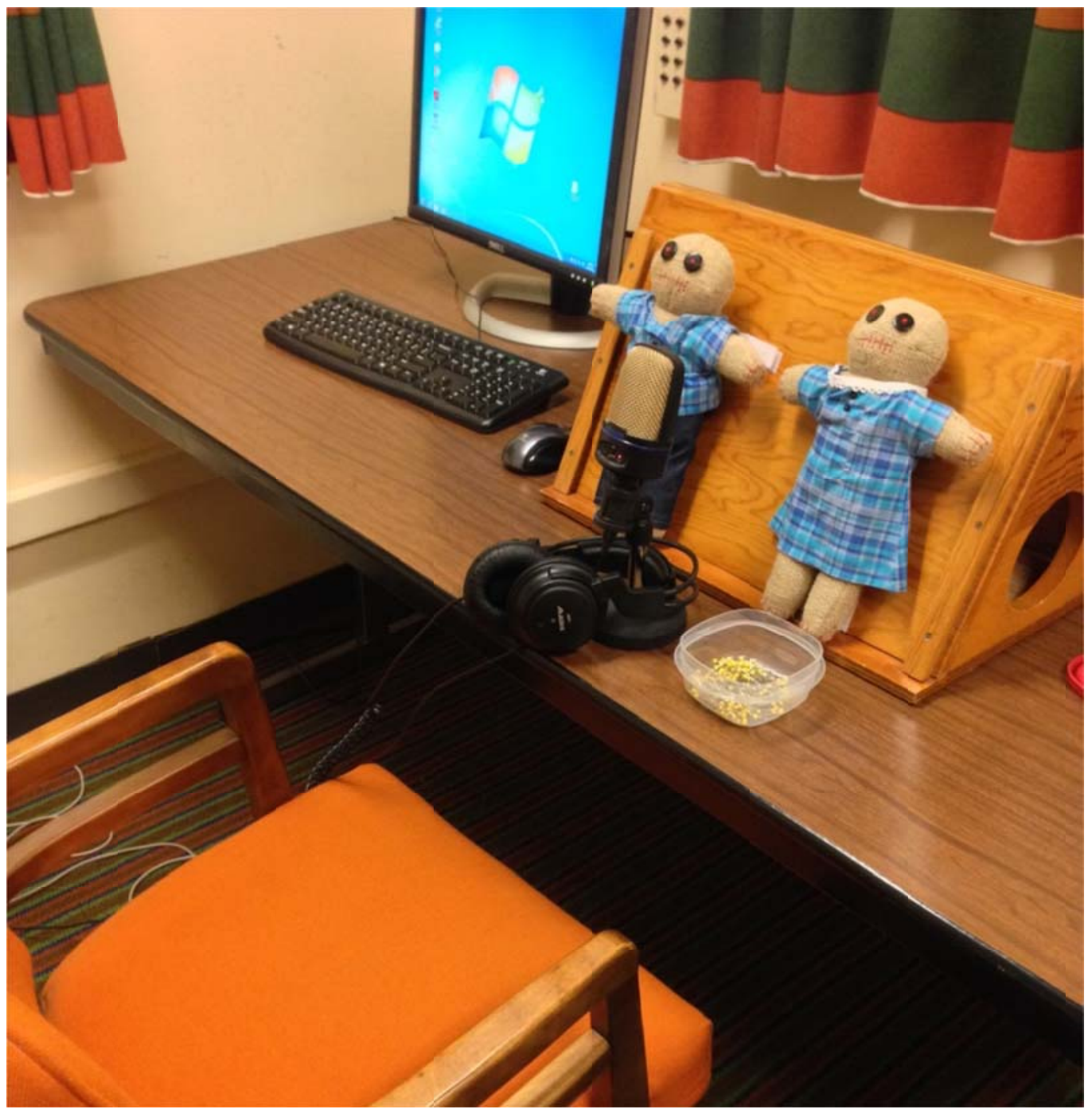


Appendix G

Voodoo Doll Task Apparatus With ATSS Microphone and Headphones

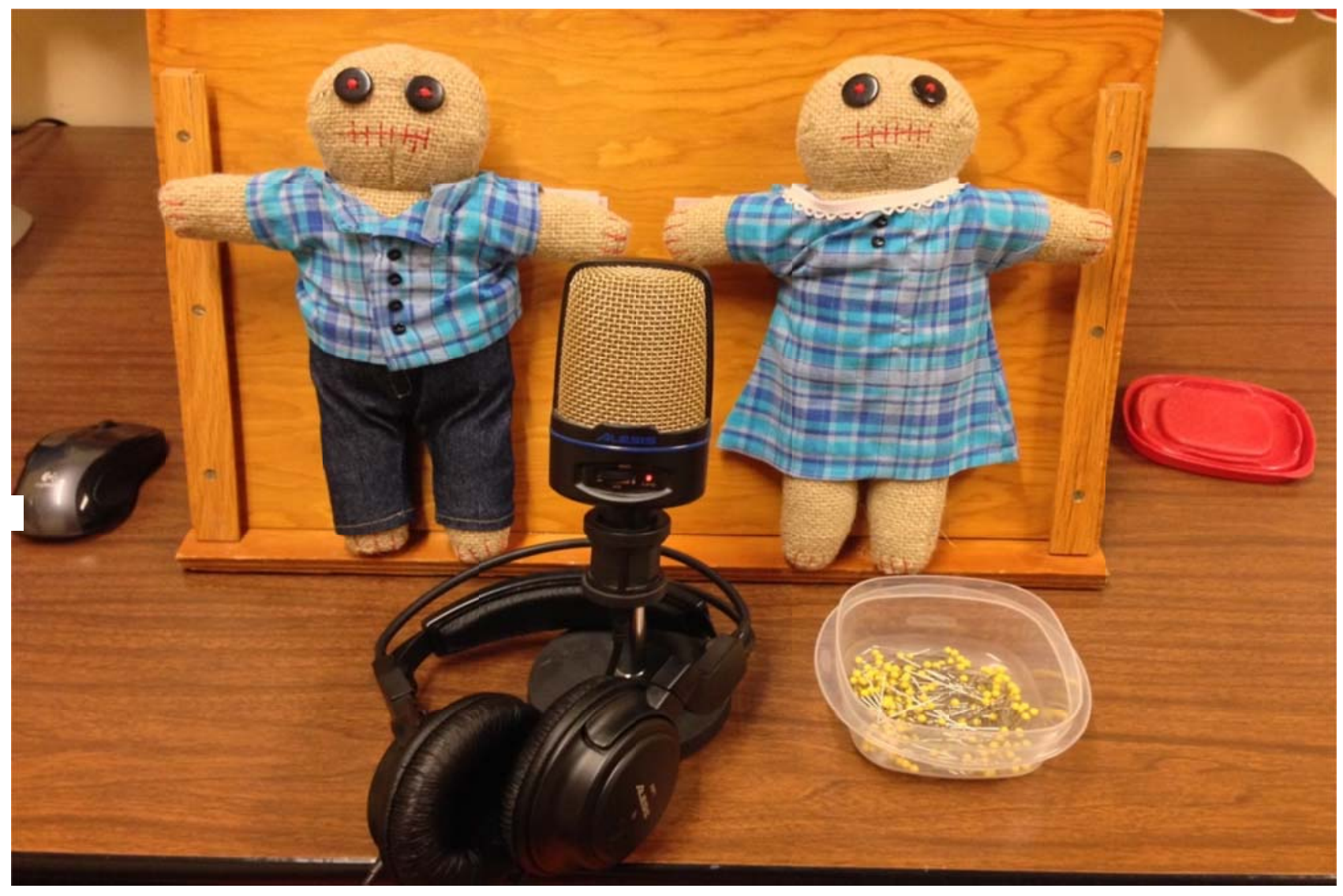


Appendix $\mathrm{H}$

Bivariate Correlations for CTS2 12-month IPV Perpetration History Variety Scores and the Outcome Measures

Outcome Measure

Psychological Aggression

Physical Aggression

Total Pin Sticks $-.11$

$-.15$

Desired Behaviors Inventory

Physical Aggression

$-.08$

.04

Verbal Aggression

.00

.06 